\title{
Augmented reality in smart retailing: A (n) (A) Symmetric Approach to continuous intention to use retail brands' mobile AR apps
}

\author{
S.R. Nikhashemi, PhD ${ }^{\mathrm{a}, *}$, Helena H. Knight ${ }^{\mathrm{a}}$, Khaldoon Nusair ${ }^{\mathrm{a}}$, Cheng Boon Liat ${ }^{\mathrm{b}}$ \\ ${ }^{a}$ Department of Marketing, College of Economics and Political Science, Sultan Qaboos University, Muscat, Oman \\ ${ }^{\mathrm{b}}$ Department of Marketing, Sunway University Business School, Malaysia
}

\section{A R T I C L E I N F O}

\section{Keywords:}

Augmented reality app attributes

Non-linear relationships

Hedonic \& utilitarian benefits

Psychological inspiration

Augmented reality app engagement

Continuous intention to use augmented reality app

\begin{abstract}
A B S T R A C T
Smart retailing has recently emerged as a new form of retail brand management enabled by novel technologies such as mobile augmented reality applications, to create better experience and value for customers. Augmented reality has also received significant attention as a growing field in marketing theory and practice. However, there is a limited understanding on how and why customer interactions with an augmented reality app can result in positive customer benefit perception, engagement and behavioural consequences. This study examines the chain of effects from AR attributes on the building blocks of continuous intention to use a shopping AR app and to pay a price premium, by incorporating the roles of a customer's benefits perception, psychological inspiration and engagement via a(n) (A)Symmetric Approach. The results support all direct hypothesised relationships among the variables, except the relationship between interactivity and utilitarian benefits, which was found to be insignificant. The study further demonstrates the moderating role of AR customisation in the proposed model, and reveals that the impact of utilitarian and hedonic benefits on shopping AR application engagement is nonlinear. Non-linearity also transpires in the impact of psychological inspiration on willingness to pay price premium. Interestingly, the findings indicate that augmented reality customisation to some extent enhances the relationships in the hypothesised model.
\end{abstract}

\section{Introduction}

Smart technologies (e.g. smart devices/mobile applications) have become an integral part of modern lifestyles and people's consumption practices, driving a global transformation of the business environment. Among the most affected industries is global retail. For example, in the US, a quarter of the total e-commerce transactions in 2019 were completed using smart devices and mobile applications (apps) and this trend in mobile apps adoption is expected to reach 45\% in 2020 (Meola, 2019). In the far east markets, South China has emerged as a 'smart consumer market' due to the exponential growth in consumers' using smart mobile devices for all their purchases (KPMG, 2018). In this wave of the growing ubiquity of 'smart lifestyles' in consumer and business markets worldwide, the retail industry has responded promptly by increasingly integrating 'smart retailing' into their business model. One aspect of smart retailing that has recently seen prolific developments is the use of mobile apps as a new smart technology and channel through which to reach and communicate customers 'needs (Rauschnabel and Hinsch, 2019).
Smart retail and mobile apps offer customers a cutting-edge, unconventional retail environment by integrating novel technologies such as augmented reality (AR) apps. These technological innovations act as "enablers of innovation and improvements in customers' quality of life" (Pantano and Timmermans, 2014: 103). AR apps combine the real world with the virtual environment creating opportunities for unique experiences in retail settings (Hilken, and Keeling, 2017). Mobile AR apps thus create enjoyable and pleasurable experiences for the customers 'on-the-go' $24 \mathrm{~h}$, through which positive behavioural and attitudinal responses can be achieved (van Esch et al., 2019). Morever, mobile AR apps also make shopping experiences easier for customers by enhancing the process of searching for information and of purchase behaviour (Park and Yoo, 2020). For example, Gap has introduced an AR app which allows the customer to select (1) a piece of clothing, (2) pick the body size and (3) an augmented reality version of the customer's outfit appears on their mobile screen which enables the customer to view how the outfit looks on them. Similarly, IKEA's AR app enables its customers to select any furniture items from the app virtual environment and locate it in their real environment view. Dacko (2017) suggests that the

\footnotetext{
* Corresponding author.

E-mail address: farhadn@squ.edu.om (S.R. Nikhashemi).
} 
experiential value that shopping AR apps offer to customers drives their remarkable popularity, with the IKEA app downloads measuring in millions.

However, the radical transformation of the retail environment introduced by the AR apps technology and its growing popularity among customers has accelerated the need for retail brands to better understand the impact of AR apps on consumer behaviour (Li et al., 2020). The unique attributes of AR are likely to enhance the practical usefulness and enjoyment of the customer's shopping experience through the app (Park and Yoo, 2020), improve customer engagement (Wang, 2020), and positively impact brand valence (McLean and Wilson, 2019) and/or purchase intentions (Loureiro, and Ali, 2020). However, empirical evidence needs to be strengthened to support these deliberations and to provide the much-needed guidelines to retail managers.

Marketing scholars have already established the need for research on the different aspects of AR apps (e.g. Grzegorczyk, and Kaczmarek, 2019). Previous studies demonstrate how AR apps influence perceived ease of use, usefulness and brand attitude (e.g. Lee, and Choo, 2017), how and why customer expected benefits result in purchase intention through AR apps (e.g. Dacko, 2017), and how AR apps expedite customer decision-making processes (e.g. Fan, and Dong, 2020; Yim et al., 2017). From the strategic perspective, studies have proposed strategic frameworks for the management of AR apps (Scholz and Duffy, 2018) and examined how companies promote AR (Feng and Mueller, 2019). However, little is known about how AR characteristics and features related to, for example, vividness, novelty, interactivity, or augmentation impact on consumer behaviour. McLean and Wilson (2019) suggest that research needs to establish the causal links between AR's attributes and shopping app engagement. Fan and Dong (2020) concur that the lack of clarity related to the relationship of AR to customer value perceptions and customer engagement is a major issue in the field. Moreover, research needs to address the knowledge gap of the impact of AR adoption on customers' attitudinal and behavioural outcomes (Fan et al., 2020b). In addition, recent industry reports show that a quarter of the downloaded AR apps are never used after the initial download (Clement, 2019). This indicates that post-adoption stages that facilitate customers' shopping app engagement need to be better understood to improve operational effectiveness of smart retail (Lee, 2018; Li and Fang, 2019).

To address these issues, this study seeks to extend the initial insights developed in the extant literature and contribute further to the classification of the causal paths in the integrative relationships of the customer-brand outcomes via mobile shopping AR app use. To this end, our contributions are three-fold. First, we build on research on customer/brand engagement in interactive and smart retail discipline (Chen et al., 2020; Fang et al., 2017; Palvia, and Chen, 2009) and develop a comprehensive framework grounded in the stimulus-organism-response model (SOR) (Mehrabian and Russell, 1974) of the effect of AR attributes of augmentation quality, vividness, novelty and interactivity of a shopping AR app on attitudinal and behavioural responses. The key premise of SOR suggests that external factors trigger consumer response. This idea has previously been applied in information system studies to identify the relationships between product attributes such as websites (Huang, and Davison, 2017) and smart apps (Fang et al., 2017; Fang, 2019), and user responses. However, as has been noted in literature (Davis, 1989; Hsiao et al., 2016), the SOR model is particularly effective for explaining the pre-adoption and initial adoption of a behaviour, rather than customers' post-adoption behaviours. In this study, the SOR model helps explain which external attributes drive user engagement and how. To explain the post-initial-adoption stages, we make use of the Uses and Gratification Theory (UGT) as previously applied in the smart apps context (Chen et al., 2020), and we also incorporate the Technology Continuance Theory (TCT) developed by (Liao et al., 2009). The TCT enables us to differentiate between the role of satisfaction and attitude as the constructs that advance the serial paths for consumers with different degree of experience with the technology. The UGT and TCT use here pertains to the paths from organism (utilitarian benefit and hedonic benefit to engagement and inspiration) to response (continuous intention to use app and willingness to pay more in the context of shopping AR apps.

The SOR stipulates that the shopping AR app features may act as triggers (S) of a user's benefit evaluation (utilitarian benefit, hedonic benefit). Testing of these specific attributes is here premised on their ability to facilitate telepresence. Telepresence refers to a psychological state of being present in the AR mediated environment (Mollen and Wilson, 2010). In this state, individuals experience cognitive and sensory arousal, control, and immersion, occurrence of which has been associated with positive behavioural outcomes (Kim and Hyun, 2016). The AR attributes of augmentation quality, vividness, novelty and interactivity are thus proposed as antecedents of functional and experiential value (Mollen and Wilson, 2010). In predicting the further serial paths, we posit that the emergence of utilitarian and hedonic customer benefits act as a confirmation of the consumer's (O) a priori expectation of the app's performance. The expectation confirmation then results in satisfaction that may subsequently lead to enhanced engagement with the shopping AR app. The enhanced engagement, particularly where driven by satisfaction emergent from enjoyment (hedonic benefit), may also invoke psychological inspiration (Rauschnabel et al., 2019). The compounded effect of satisfaction confirmation within the serial paths hitherto drives further engagement with the app, as well as enhances the engagement. This process is motivated by the user's emerging positive attitude towards the app.

The resultant behavioural engagement intention to continue using the app and a willingness to pay a price premium for the product represent the final response (R). The final response is thus considered to be the result of the emergence of gratification with each confirmed expectation. Accordingly, the serial paths between attributes and benefits, and benefits and engagement (as well as inspiration), and the formation of a positive attitude as an overall evaluation of the shopping AR app (Liao et al., 2009; Rauschnabel et al., 2019) together trigger the intention to usage continuance. In terms of satisfaction, this is expected to initially arise as a result of negative expectation-disconfirmation of benefits (Liao et al., 2009), and, in the next serial path, of satisfactory engagement with the app and the inducement of inspiration. The intention to continue engaging with the app is thus a result of satisfaction for novice shopping AR apps users. For repeat users whose positive experience is confirmed in subsequent uses of the app, the initial satisfaction that motivated repeat use is further strengthened through the emergence of a positive attitude triggered by the overall positive evaluation of the experiences with the specific shopping AR app (Chen et al., 2020; Liao et al., 2009; Rauschnabel et al., 2019).

Second, we incorporate AR customisation into the proposed model. Customisation is a distinct feature of shopping AR apps that may not only increase the sense of customer value attainment but it inherently actively engages customers with the content to create a personalised experience (Trivedi and Trivedi, 2018). As a relatively new concept in AR marketing literature, scholars have suggested that the behavioural and attitudinal consequences of AR customisation need to be examined (Fang, 2019; Li and Fang, 2019; McLean, 2018). To respond to this call, this study incorporates the moderating role of AR customisation in the relationship between AR attributes and utilitarian and hedonic benefits, as well as between the utilitarian and hedonic benefits and shopping AR app engagement, and psychological inspiration.

Finally, recent consumer behaviour studies have developed their proposed theoretical models based on variance or covariance structural equation modelling (SEM), through which only the linear relationships can be detected. However, as stated by Kock (2020a,b) and Nikhashemi, Jebarajakirthy and Nusair (2019), the nature of association in behavioural studies tends to be non-linear. To address this inconsistency in prior research, the present study applies nonlinear based SEM to identify the actual relationships among the variables.

This study provides a number of theoretical and practical insights to 
the marketing body of knowledge in the following areas. Contributions are made to AR marketing, consumer behaviour and branding literature, particularly in the smart retail setting. Theoretically, by grounding the results in the SOR model complemented by the satisfaction and attitudinal premises of the UGT and TCT, we offer an integrated framework for examining customer interactions with shopping AR apps across all stages of adoption. The results clarify the links between AR attributes and customers' utilitarian and hedonic benefits. We also demonstrate the impacts of utilitarian and hedonic benefits on psychological inspiration, and on customers' behavioural outcomes. The moderating role of AR customisation in the hypothesised serial relationships between AR attributes, customer benefits, and attitudinal and behavioural consequences is also established, as are the non-linear relationships among some of the exogenous and endogenous variables (e.g. hedonic and utilitarian benefits toward shopping AR app engagement). Thus, the study extends the literature by empirically demonstrating the previously overlooked actual relationship among some of the variables (nonlinear). Practically, the findings here are expected to grant app developers, consumer behaviour analysts and AR marketers more detailed understanding of the predictive role of smart technologies on consumer behaviour. Such knowledge offers contributions towards the development of competitive marketing strategy in smart retail settings.

The proceeding sections provide the theoretical underpinnings to our overarching research question: What are the aggregate mechanisms that operate the serial paths from shopping AR app attributes as stimuli to continuous intention to use an app and a willingness to pay a premium as the consumer's behavioural response? and a set of sub-questions to guide the aggregate mechanisms: How do utilitarian and hedonic benefits resultant from shopping AR attributes influence customer engagement with the app and psychological inspiration? How does customer engagement with the app influenced by utilitarian and hedonic benefits as a) an autonomous construct, and b) as influenced by psychological inspiration influence the customer's continuous intention to use the app and the willingness to pay a price premium. How does psychological inspiration influence the customer's continuous intention to use the app and their willingness to pay a price premium? We further ask: How does the customer's ability to personalise content through AR customisation attribute impact the mechanisms between AR attributes and utilitarian and hedonic benefits, as well as between the utilitarian and hedonic benefits and shopping AR app engagement, and psychological inspiration?

\subsection{Theoretical model and hypotheses development}

AR constitutes functional characteristics and features that are distinct to those of other e-commerce technologies (Mollen and Wilson, 2010). This renders the extant theorising deficient to explain the effect of technology on customer-brand relationships in AR contexts (Yim et al., 2017). AR apps researchers need to focus on explaining which shopping AR app characteristics and features lead to what type of customer responses to enable both theoretical and practical understanding of how to engage customers, and how to sustain and further develop the initial engagement. This study proposes that the integrated framework grounded in SOR model (Mehrabian and Russell, 1974), UGT (Chen et al., 2020; Hsiao et al., 2016) and TCT (Liao et al., 2009) offers an effective conceptual foundation for developing integrated, serial relationships modelling of the antecedents (stimulus), mechanisms (organism) and responses related to shopping AR apps across adoption stages.

Moreover, many information systems (IS) studies have demonstrated that beyond the internal reactions, product attributes drive specific actions such as behavioural intentions (Fan et al., 2020a; Fang et al., 2017; McLean and Wilson, 2019; Park and Yoo, 2020; Poushneh and Vasquez-Parraga, 2017; Rauschnabel et al., 2019; Verhagen et al., 2015). For example, Fang et al. (2017) demonstrate that the SOR model is particularly suited to understand which product attributes drive customer engagement and how this occurs when customers engage with mobile travel apps. Building on this logic, we utilise SOR as an over-arching framework for structuring the serial paths across stimuli represented by the shopping AR app attributes and the organism or internal processes (to include psychological inspiration). The internal processes act as a system through which the user evaluates the experiences and which result in a specific set of responses related to the initial engagement. To explain behavioural responses beyond the initial engagement (Hsiao et al., 2016), we build on empirical research within IS that has a) successfully utilised the key premises of UGT to model the determinants of continuance usage (Chen et al., 2020; Hsiao et al., 2016) and b) proposed and empirically tested TCT (Liao et al., 2009) as an integrative model for explaining and predicting customer behaviour in accepting as well as continued usage of technology, such as shopping AR apps. These studies concur that satisfaction and attitude are key predictors of initial and continued adoption behaviour, respectively. The findings of these studies suggest that our proposed framework grounded in SOR and complemented by the key premises of UGT and TCT, is appropriate for modelling the serial paths in the continuous intention to use shopping AR apps in retail brands.

\subsection{Shopping AR app attributes - the stimuli and customer benefits}

The SOR model explains that environmental stimuli affect the user's internal states in that they trigger a cognitive and emotional response of the consumer and influence their decision-making. A set of 'internal processes and structures' made up of "perceptual, physiological, feeling, and thinking activities" distinct to each consumer (O) function the processing of external stimuli into specific attitudinal and behavioural responses (Bagozzi, 1986). Extant IS studies have established that characteristics of an offering act as environmental stimuli as they have a significant impact on whether and how customers engage with technology (Venkatesh et al., 2016). Smart technology attributes refer to the distinct characteristics and features that make the technology unique, functional and appealing to its users (Rauschnabel et al., 2019). Functional features lead to the practical benefits related to, for example, more efficient task accomplishment resulting in the attainment of utilitarian benefits by the individual (Picot-Coupey et al., 2020). In contrast, enjoyment, as derived from aesthetics and pleasure, represent hedonic benefits (Rese et al., 2017).

Interactivity is considered one of the principle constructs related to the influence of digital/smart technology on customer experience (Mollen and Wilson, 2010). Accordingly, interactivity has been suggested as a unique attribute of AR due to its implied ability to drive attitudinal and behavioural outcomes (McLean and Wilson, 2019; Yim et al., 2017). Yim et al. (2017) empirically test the effects of interactivity together with vividness and novelty as AR app attributes, on customer responses. The study reports that, mediated by immersion, interactivity and vividness positively influence media usefulness and enjoyment. The realisation of a perceived customer benefit results in an attitude towards the AR app, and through this construct, leads to a positive purchase intention. The significant positive effect of interactivity and vividness on customer response, however, weakens with an increased familiarity as the function of novelty attribute. Similarly, McLean and Wilson (2019) examine AR app interactivity, vividness and novelty, and establish their relationship with perceived ease of use, usefulness, enjoyment and subjective norms. The research confirms positive influence of the three AR app attributes on ease of use, usefulness and enjoyments. In addition, a positive relationship between the four technology attributes and customer brand engagement is confirmed, which in turn bears positively on satisfaction with the experience, and future brand intentions.

However, Javornik (2016) rejects interactivity as a salient feature of $\mathrm{AR}$ in its influence on perceived control and perceived responsiveness, compared to non-AR environments. Javornik (2016) argues that "AR is not just another more interactive technology, but functions in a different way" (p. 1002). These inconsistent findings suggest that AR interactivity 
requires a more detailed examination to clarify its salience in consumer behaviour.

Yim et al. (2017) propose that interactivity constitutes two complementary perspectives: technological outcome as related to structural properties of AR apps and user perception that considers interactivity from an experiential standpoint related to cognitive processing and involvement in the activity (Mollen and Wilson, 2010). The authors suggest that the perceptions of the users of the shopping AR app to experience the sense of interactivity from using the app offers an appropriate lens for studying buyer behaviour. This is because the effect of interactivity in AR on customer-brand relationships is determined by the ability of AR to induce a sense of interactivity. Although customer perceptions of interactivity may be influenced by technological components of AR interactivity such as speediness in manipulation, accuracy of mapping, and the range of possibilities to alter the content (Steuer, 1992), Mollen and Wilson (2010) disagree. The authors argue that it is the experiential aspect of interactivity related to "the degree to which the user perceives that the interaction or communication is two-way, controllable, and responsive to their actions" (p. 921) that determines brand related outcomes.

By extending the existing studies on AR interactivity to the stipulation of the SOR model that shopping AR app attributes may act as triggers (stimuli) of a user's benefit evaluation (utilitarian benefit, hedonic benefit), the following hypothesis is proposed;

H1. Shopping AR app interactivity is associated with:

a) utilitarian benefit.

b) hedonic benefit.

Extant literature asserts that the salient feature of AR apps that stimulates customer interest is the ability of AR to blend the real with the virtual, in other words, to augment reality (Javornik, 2016). The customer perceived quality of the augmentation experience is thus likely to be the focal factor that determines whether the customer will be induced to interact with the technology. Hilken et al. (2017) utilise situated cognition theorising with respect to an individual's perception of AR to offer a constructive platform for elaborating the components of AR that constitute the perceptual quality of an augmentation experience. The authors establish the importance of physicality in reducing complexity of customer decision-making in online environments and introduce spatial presence as a construct that influences AR related cognition. Spatial presence describes a psychological state where the person "feels physically situated in a different location and perceives possibilities for action" unburdened by thinking about the technology behind the experience (Hilken et al., 2017: 889). It is enabled by the interaction of its two distinct characteristics: environmental embedding (EE) and simulated physical control (SPC). EE offers customers novel experiences as "it visually transforms physical reality by superimposing virtual elements directly into the real-time environment through a screen or projector" (Javornik, 2016: 987). SPC enables the customer to interact with the product via haptic simulation in a way that mirrors the movements used in the evaluation of physical products (Huang and Liao, 2015).

Building on this conceptualisation of EE and SPC, Rauschnabel et al. (2019) refer to augmentation quality as the degree to which the AR experience appears realistic, as enabled by the seamless merging of the real and virtual. Fan et al. (2020) further elaborate on the EE and SPC constructs through cognitive perspective of users' information processing. SPC and EE are implemented through cognitive loading and cognitive fluency (Bertele, and Laer, 2020), which describes the relative complexity associated with interacting with the stimuli (Fan et al., 2020). The more realistic (cognitively fluent) the augmentation experience facilitated by SPC and EE (Hilken, and Keeling, 2017) and the lower the cognitive load (induced by the technology-mediated experience), the higher the level of perceived augmentation quality. The process results in greater value and benefit perception by AR app users, triggering satisfaction.

The quality of smart technologies is widely recognised in e-commerce to impact on customer psychological processes (Fang et al., 2017). Poushneh (2018) reports that customers evaluate augmentation quality by the practical value it serves (utilitarian benefit) and the enjoyment (hedonic benefit) that derives from the experience. Kim and Forsythe (2008) further find that a 3-D augmented-reality shopping experience that closely matches real shopping experience allows customers to verify a product's attributes and quality before purchase, demonstrating its practical usefulness (utilitarian benefit). Based on the arguments made above, we hypothesise:

H2. The quality of the augmented reality within the shopping app is associated with:

a) utilitarian benefit.

b) hedonic benefit.

Evidence in extant literature indicates that vividness and novelty, which are considered to be among the highly salient attributes of AR, may stimulate customer-brand-related responses (McLean and Wilson, 2019). Vividness in AR refers to the richness of the mediated environment as generated through the shopping AR app in terms of the aesthetic appeal and the quality of the product presentation. Yim et al. (2017) describe vividness as an outcome of the integration of the sensory experience of actual objects with non-sensory experience of an imaginary object that enables clear visualisation, and highlight the positive effects of vividness on positive customer responses. Mediated by immersion, vividness positively influences media usefulness (utilitarian benefits) and enjoyment (hedonic benefits), which then drives attitudinal and behavioural constructs. The authors further report that the effect of vividness on customer response weakens with increased familiarity as a function of novelty.

Novelty of AR in shopping AR apps refers to AR's ability to deliver previously unencountered experiences in online shopping. McLean and Wilson (2019) define AR novelty not as its 'newness' in online retail, but in "the new, unique, personalised, novel content (stimuli) experienced each time through the AR display" (p. 213). Fang (2019) suggests that personalised innovative functions make customers curious and prompt them to further engage in searching for new information and exploration. For example, van Esch et al. (2019) find that anthropomorphism, in terms of endowing AR with human characteristics and qualities, influences customers' perceptions of innovativeness/novelty of an AR app. Furthermore, Rauschnabel et al. (2019) state that AR apps with unique features, such as novelty, vividness, quality, etc., can stimulate its users' functional and enjoyment experiences and, therefore, it expedites the utilitarian and hedonic benefit perception process. Thus, the following hypotheses are proposed:

\section{H3. Shopping AR app vividness is associated with:}

a) utilitarian benefit.

b) hedonic benefit.

H4. Shopping AR app novelty is associated with:

a) utilitarian benefit.

b) hedonic benefit.

\subsection{Utilitarian and hedonic benefits serial path consequences}

Building on the UGT and the theory of planned behaviour (Ajzen, 1985), numerous studies within the IS field suggest that satisfaction and attitudes are powerful explanatory variables for addressing the 
complexity of adoption behaviour (Chen et al., 2020; Lee, and Chan, 2015; Hsiao et al., 2016; Lee, 2018; Li and Fang, 2019; Liao et al., 2009; Rauschnabel et al., 2019; Yim et al., 2017). Within this research stream, satisfaction is commonly considered as a transient and experience-specific construct related to a post-consumption judgement of a specific experience. Attitude, on the other hand, is the extent to which the individual develops positive or negative feelings towards an offering overall (Liao et al., 2009). Although an attitude is sometimes considered as a persistent personal disposition, studies on AR apps have built on the perspective of Schwarz (2007) that attitudes are time and context-bound evaluative judgement developed from information currently to hand (Rauschnabel et al., 2019).

Building on these perspectives, we propose that satisfaction is likely to be the determinant of progress along the hypothesised serial paths. However, achievement of post-initial-adoption behavioural outcomes entails the emergence of a positive attitude towards the shopping AR app, as driven by the effect of compounded satisfaction of each serial path via satisfactory engagement and the experience of inspiration. Our theorising is grounded in extant research as follows: Liao et al. (2009) suggest that continued usage is likely to be driven by the user's inner cognitive and affective judgements such as attitude. Hsiao et al. (2016) confirm that habit and satisfaction as a consequence of perceived enjoyment (hedonic benefits) are good predictors of continuance intention, with satisfaction being reported "key and the most influential factor in explaining users' continuance of using social apps" (p. 351). However, Li and Fang (2019) find that satisfaction in terms of expectation confirmation alone does not have a direct influence on continuance intention. Chen et al. (2020) utilise UGT to study continuance usage intention in the context of sport and leisure app. The authors differentiate between low frequency and high frequency users to further clarify the relationship between habit, satisfaction and post-adoption behaviour. Satisfaction is found to be the predictor of continued willingness to use by low frequency users but not for the high frequency users, whose post-adoption behaviour is predicted by habit. This makes an important distinction between early adopters with little experience and experienced adopters.

This study focuses on shopping AR apps, a relatively new phenomenon where the majority of customers are initial users. Thus the key focus is on satisfaction and attitude formation. Liao et al. (2009) develop the TCT model to demonstrate that satisfaction is a significant predictor only for initial adopters who are unable to fully appreciate the performance of the technology due to a lack of familiarity with it. For long-term adopters, attitude is the key construct. At the initial stage, users are only able to evaluate (whether consciously or subconsciously) the extent to which the expected performance was realised. After the initial use, however, the user no longer judges the performances on pre-adoption expectation but builds on the initial perceived usefulness of the technology to decide whether to continue using it. As the user begins to evaluate the actual performance, attitude towards the system begins to be formed which determines further engagement and intention to adopt long term. With repeat, regular use, attitude is fully formed and becomes the principal predictor of the long-term adoption (Liao et al., 2009), underpinned by habit (Hsiao et al., 2016).

Building on this logic of the TCT model (Liao et al., 2009), the organism-response aspect of the SOR model can be broken down into serial paths from benefits to customer engagement to psychological inspiration to continued intention to use the app and willingness to pay more. These paths can be split into distinct interactions that the user experiences and evaluates for the purposes of determining satisfaction. Although the satisfaction with each path is considered to be transient, related only to the specific path (Liao et al., 2020), each confirmation of expectation propels the process forward, strengthening engagement. It also acts as a re-enforcer of the overall satisfaction and contributes towards the development of overall positive judgement (attitude) towards the shopping AR app. The proceeding sections discuss and develop hypotheses for each serial path.

\subsection{Customer engagement}

Engaging with a branded app entails significant dedication and commitment from a customer that may influence the customer's disposition towards the branded app. The resultant brand valency is likely to determine the strength of the customer-brand relationship (Scholz and Duffy, 2018). The degree to which positive customer manifestations emerge is closely related to the accrued benefits that customers perceive noteworthy (Kumar and Kumar, 2019).

Verhagen et al. (2015) empirically demonstrate the relationship between hedonic and utilitarian benefits and customer engagement intention in virtual environments. Fang et al. (2017) utilise an experiential-cognitive mediation process to establish that psychological engagement not only affects behavioural engagement intention directly, but it also influences the engagement intention via utilitarian and hedonic benefits perceptions. Similarly, Yim et al. (2017) report that usefulness (a utilitarian benefit) and enjoyment (a hedonic benefit) result in more positive attitudes toward AR enabled mobile technology.

A number of studies report perceived usefulness as a significant variable that influences positive attitudes towards a branded shopping app (Lee, 2018), sustainable relationship behaviour toward using AR (Huang and Liao, 2015), and AR app engagement generally (McLean and Wilson, 2019). Hilken et al. (2017) explain that the utility of AR lies in its ability to offer virtual trial of the product. Moreover, the enhanced information offered to customers mitigates the mental burden of visualising how, for example, a pair of sunglasses would look when worn (van Esch et al., 2019). Dacko (2017) found that shopping AR apps provide efficiency or better shopping value and although the apps are able to entertain, entertainment does not rate as highly by users as efficiency. Likewise, Rauschnabel et al. (2019) affirm that attitude toward using an AR enabled app is primarily driven by utilitarian benefits.

However, Kim and Forsythe (2008) contend that virtual try-ons are typically associated with high entertainment. This denotes hedonic benefits. Pantano and Servidio (2012) classify enjoyment as a major influencing variable for customer's satisfaction in AR enabled shopping environments, as it permits clients to live a more engaging experience during their interactions with the point of sale. Likewise, McLean and Wilson (2019) highlight a positive relationship between enjoyment and brand engagement as an outcome of interactions with shopping AR apps. Rauschnabel et al. (2019) test the relationship between AR apps and customers' attitudes toward AR through a mediated effect of utilitarian and hedonic benefits. They find that although both influence the attitude towards the app, only hedonic benefits lead to psychological inspiration. However, in extant literature inspiration is typically seen as a motivational state activated by an external trigger that drives the accomplishment of a novel task (Thrash et al., 2014) and which facilitates new possibilities that may result in new ideas (Böttger et al., 2017). Although existing research in AR shows that AR-triggered visualisation of new possibilities facilitates exciting experiences (Poushneh, 2018), the novel visualisation is likewise instrumental in achieving for example greater economic value from the shopping experience (Dacko, 2017). Li and Fang (2019) concur that the more benefits customers derive from interacting with shopping apps, the more engagement they experience. Thus, we hypothesise that:

H5. Utilitarian benefit is associated with:

a) shopping AR app engagement.

b) psychological inspiration.

H6. Hedonic benefit is associated with:

a) shopping AR app engagement,

b) psychological inspiration. 


\subsection{Shopping AR app engagement and psychological inspiration serial path consequences}

Prior studies assert that customer benefits can lead to enhanced behavioural brand engagement (Fang et al., 2017; Verhagen et al., 2015). Fang (2019) suggests that an engagement response is an outcome of an exchange motivation which arises when individuals feel compelled to reciprocate for accrued advantage. In this sense, the hedonic and utilitarian benefits emergent from shopping AR app experience drive the customer to reciprocate by continuing to engage with the app (Wang, 2020) and to establish a sustainable relationship with that brand (Fang et al., 2017). Lee and Chan (2015) further validate that confirmed benefits lead to a continuous intention to use the app, and the intention to purchase also increases. Li and Meshkova (2013) establish that rich visual cues in virtual environments lead to increase in purchase intentions directly, as well as indirectly via utilitarian and hedonic benefits. Alizadeh, Quach, and Hamelin (2020) recently attest that people with positive valence towards an app are more inclined to make in-app purchases. Similarly, Poushneh and Vasquez-Parraga (2017) ascertain that customers' willingness to pay increases when customers are provided AR-enriched experiences that are entertaining and interactive, such as the provision of enhanced augmentation quality and adjustable 3-D images. Thus, we hypothesise:

\section{H7. Shopping AR app engagement is associated with:}

a) continuous intention to use the shopping AR app.

b) willingness to pay price premium.

Extending the previous relational path between customer benefits and psychological inspiration in H5, we expect this serial relationship to continue in two directions. First, psychological inspiration will lead to a behavioural response directly. Second, there will be an indirect relationship via customer engagement with the brand, specifically, with the AR enabled shopping app. For the former, Böttger et al. (2017) demonstrate that in situations where customers seek and are open to new ideas, such external stimuli can evoke inspiration. Inspiration here is triggered through, amongst other factors, the acquisition of functional and hedonic benefits, which may subsequently initiate a change in consumption habits. The authors suggest that when customers are 'inspired-by' the benefits derived from partaking in an AR experience, they become 'inspired-to' actualise a behavioural, attitudinal and/or emotional consequence. Inspiration thus represents a potentially significant mechanism through which benefits move customers towards behavioural outcomes.

Böttger et al. (2017) also examine the indirect relationship and establish that emotional and attitudinal outcomes in terms of positive effect, delight, transcendent customer experiences, as well as brand attachments inspire customers to further engage with the brand. Although Rauschnabel et al. (2019) similarly report a significant and positive influence between inspiration and changes in brand attitude, they reject the positive effect of inspiration on attitude toward the AR app. In this regard, Böttger et al. (2017) explicate that customer-app engagement through inspiration is constitutive of both emotional and attitudinal effects. Inspiration may not drive positive attitude towards the app, yet the potential of inspired-to transcendent customer experiences, positive feelings and delight triggered by the interaction that also denote customer brand engagement, may result in enhanced behavioural outcomes. In addition, Fang (2019) ascertains that when a customer perceives a branded app as delivering unique instrumental and experiential benefits, the customer develops positive emotions and so is likely to feel inspired to explore more. Moreover, the emotions are likely to strengthen the valence towards the brand, prompt a repeated use of the branded app and strengthen the customer's willingness to pay more. We thus suggest that hedonic and utilitarian benefits evoke emotional and attitudinal outcomes related to shopping AR app engagement, where this heightened sense of emotional and attitudinal engagement leads to positive intention towards repeat use of the app. This underpins the following set of hypotheses:

H8. Inspirational intention is associated with shopping AR app engagement.

H9. Inspirational intention is associated with:

a) continuous intention to use the app.

b) willingness to pay price premium through the shopping AR app.

\subsection{Moderating role of shopping AR app customisation}

The role of customisation as a significant construct related to customer experience within virtual environments has been raised in literature previously (Magrath and McCormick, 2013; McLean, 2018). Magrath and McCormick (2013) hypothesise the role of customisation as a specific marketing design stimulus in mobile commerce that enables customers to personalise the experience according to their own preferences (Fang, 2019; McLean and Wilson, 2019). Customisation can thus be considered as a focal dimension for measuring customers' perceptions of the relative advantage of an offering (Fang et al., 2017).

Customisation has been linked with benefits ranging from providing a sense of agency or self (Javornik, 2016; Smink et al., 2020), improved effectiveness of task completion in travel app use (Fang et al., 2017), enhanced enjoyment and immersion in the experience (Lee, and Chan, 2015), and enhanced positive attitudes towards smart technology (Li and Fang, 2019). Smart retailers are ideally positioned to drive customer engagement through customisation as app users can easily adjust and set, for example, their personal details, preferences and location visibility (Magrath and McCormick, 2013). Although the importance of customisation is frequently implied as an important attribute in AR research, its effects appear not have been fully examined by extant research. Aside from a comment by (Poushneh, 2018) that a user's information quality is partially determined by the level of customised content offered to the user, McLean (2018) appears to be the sole study to examine the construct fully within the mobile shopping apps context. McLean (2018) reports that customisation of an app enhances the positive effect of the technology-related, social and self-related variables of perceived ease of use, perceived usefulness, convenience and enjoyment on engagement with the app and, subsequently, on behavioural brand outcomes.

Customisation is yet to be fully examined in an AR app context. However, by building on McLean's (2018) findings, we expect customisation to moderate the effects of the four outlined attributes to deliver utilitarian and hedonic benefits for shopping AR app users. Therefore, we hypothesise:

H10. Shopping AR app customisation moderates the association between:

a) shopping AR app interactivity and utilitarian benefit.

b) shopping AR app interactivity and hedonic benefit.

c) the quality of the augmented reality within the shopping app and utilitarian benefit.

d) the quality of the augmented reality within the shopping app and hedonic benefit.

e) shopping AR app vividness and utilitarian benefit.

f) shopping AR app vividness and hedonic benefit.

j) shopping AR app novelty and utilitarian benefit.

h) shopping AR app novelty and hedonic benefit.

Customisation is a distinct feature of shopping AR apps that may not only increase the sense of customer value attainment, but it inherently actively engages customers with the content to create a customised 
experience (Hsiao et al., 2016). As previously discussed, the Magrath and McCormick (2013) hypothesis links customisation with potentially significant effect on customer experience. Cheung et al. (2015) corroborate the significance of the effect in virtual gaming and McLean (2018) substantiates that customisation is a key construct in encouraging customers to engage with a retailer's app in that customisation strengthens the effect of the app attributes on engagement with the shopping apps. McLean (2018) further demonstrates that enabling customers to customise preferences, filter tools and content has a positive effect on brand attitudes and brand loyalty. As recently concluded by Kumar et al. (2020) in a summary of the impact of new-age technologies on marketing, "customers are more engaged with the firm when they receive offerings and communications that are customised to their needs and preferences". We thus hypothesise:

H11. Shopping AR app customisation moderates the association between:

a) utilitarian benefit and shopping AR app engagement.

b) utilitarian benefit and inspirational intention.

c) hedonic benefit and shopping AR app engagement.

d) hedonic benefit and inspirational intention.

The current study proposes the above theoretical framework based on the arguments outlined in the review of the extant literature. As depicted in Fig. 1, the theoretical framework is composed of 11 reflective constructs, namely: AR quality, AR novelty, AR interactivity, AR vividness, AR customisation, utilitarian benefit, hedonic benefit, shopping AR app engagement, psychological inspiration, continuous intention to use shopping AR app, and willingness to pay price premium.

\section{Methods}

\subsection{Sampling approach and sample size}

The study utilises non-probability, purposive sampling approach in data collection as the sample size is not well defined (e.g. we were unable to identify the exact number of shopping AR app users). For this purpose, the study employs online data collection in the form of panelbased judgmental sampling of Malaysian's customers with an experience with at least two AR apps. The selection was further limited to individuals who possess sufficient experience with shopping AR apps with any of the following brands: Gap, IKEA or Amazon, as available in android play store or iOS Apple store platforms (refer to Appendix $\mathrm{C}$ for further visual explanation of each app). To ease and expedite the process of data collection, financial incentive was offered to respondents. The survey process was designed to ensure that only customer who downloaded the AR app from the aforementioned platforms (e.g. Play store Android, iOS Apple Store), retained the app for a minimum of one month, and used the features of the app more than once, participated in the survey. Screening questions prior to data collection ensured compliance with the criteria. For instance, the target sample were asked to answer the following questions before completing the questionnaire: (1) How often do you normally use augmented reality app? (2) How long ago did you download your shopping augmented reality app? Only those respondents who satisfied the stated criteria were invited to complete the questionnaire. Respondents who did not meet the criteria were asked to exit the survey.

Scholars have long polemised the 'right' sample size. Sekaran and Bougie (2016) suggest that an adequate sample size can fall between 300 and 500, whereas (Hair et al., 2016) maintain that the calculation of a sample size depends on resource constraints. Besides (Byrne, 2016), proposes that power analysis can be considered as an appropriate approach to determine the sample size prior to applying any SEM models. This study applies two approaches, namely "inverse square root" and "gamma-exponential" advocated by Kock and Hadaya (2018) as an efficacious approach to detect an acceptable sample size. This procedures simulate the Monte Carlo experiments, and hence generate estimates similar to the values generated using the Monte Carlo approach (Kock, 2020a,b). The inverse square approach is inclined to overestimate the essential sample size required for the SEM. To address this issues and to strengthen sampling justification, the

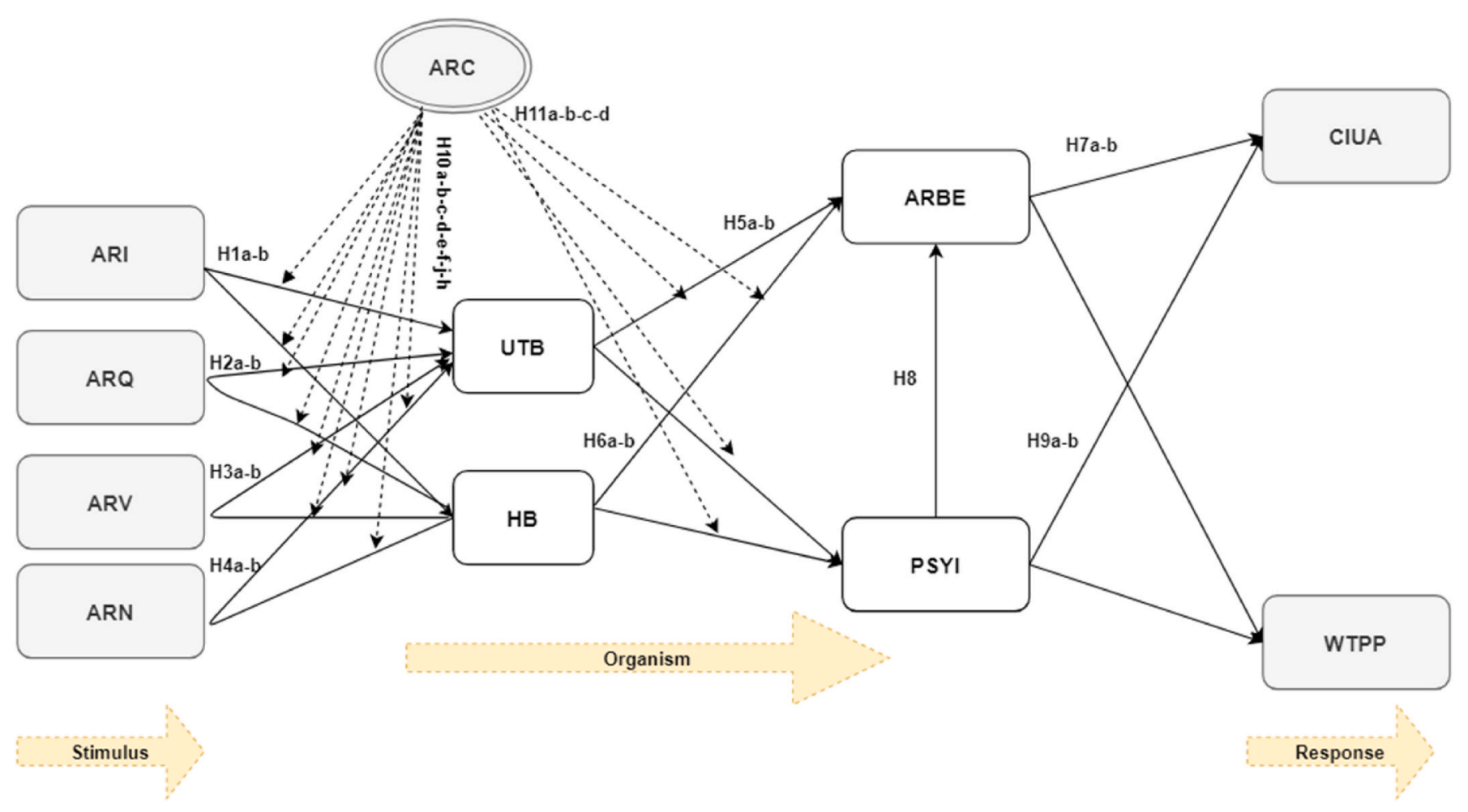

Fig. 1. The proposed conceptual model (Insert Here). 
gamma-exponential technique should also be utilised as it arguably offers more precise estimates compared to inverse square method (Kock and Hadaya, 2016).

Building on the combined logic of "inverse root square" and "gamma-exponential" approaches, the minimum required sample size for the current study is 279 and 261, respectively (refer to Appendix B). The declared estimates were generated based on specific default values: 0.120 is considered as the minimum absolute accepted path coefficient, 0.05 , is used for significant p-value level, and 0.80 is considered as the acceptable required power level (Kock and Hadaya, 2018). The study has thus used the same default level, yet it has considered a greater power level (0.95) to ensure the rigidity of the suggested sample size. Since the actual sample size of the current study after removing the incomplete and missing values questionnaire exceeds the above-mentioned threshold levels (301), we can conclude that the required sample size for the present study is met.

\subsection{Measures}

All exogenous and endogenous constructs of this study are measured with items presented in extant literature (see Table 2). However, the wording of the items was in some cases modified to contextualise it within the study. To measure all endogenous and exogenous variables, 7- point Likert scale was employed, where 1 is assigned to represent "strongly disagree" and 7 "strongly agree".

\subsection{Statistical approach}

SEM is widely used in marketing and behavioural studies and its inevitable role in dealing with reflective, formative and complex models is undeniable (Hair et al., 2016). However, until recently, the SEM had shortcoming due to not being able to identify non-linear relationships among constructs. The majority of studies in prior literature, particularly in marketing and consumer behaviour studies, focus predominately on identifying linear relationship among variables. Focusing solely on the detection of linear relationships, however, does not construe the actual relationships. This is problematic due to the potentially non-linear nature of relationships among the exogenous and endogenous variables in marketing and consumer behaviour (Kock, 2020a,b; Nikhashemi et al., 2019). WarpPLS offers an appropriate statistical approach to address this shortcoming through its capacity to identify the linear relationships and non-linear relationships (Warp) among variables concurrently (Kock, 2018). Moreover, WarpPLS computes two unique sets of global model fit indices, namely the classical model fit index and correlation matrix index, which are compatible with both factor-based and composite-based SEM (Kock, 2020a; Nikhashemi et al., 2019). Building on the above discussion combined with the nature of this study, WarpPLS is employed as a statistical approach for analysing the findings of this research.

\section{Results}

\subsection{Demographic characteristics}

Table 1 represents the demographic profile of the respondents in this study. As indicated in Table 1, 48\% of the sample size are males, whereas $52 \%$ are females. The distribution of age is reasonably similar among all age groups and the majority of the respondents' ages falls between 26 and $33(30.9 \%)$, followed by $29.3 \%$ of those between 34 and 40 years old. As further shown in Table 1, ethnicity of the sample distribution consists of Malaysians representing 41.6\%, Chinese $34.5 \%$, followed by Indian and others who represent $12.6 \%$ and $11.2 \%$ of the population respectively. Additionally, majority of the respondents' (52.6\%) terminal degree is undergraduate, $16.8 \%$ postgraduate and $7.9 \%$ A-level. In terms of respondents' experience with shopping AR apps, more than $50 \%$ are weekly users, followed by $34.2 \%$ biweekly users, and $8.2 \%$ and
Table 1

Sample profile.

\begin{tabular}{lll}
\hline Characteristics & $N$ & Percentage \% \\
\hline Gender & 146 & 48 \\
Male & 158 & 52 \\
Female & & \\
\hline Age & 74 & 24.3 \\
18-25 & 94 & 30.9 \\
$26-33$ & 89 & 29.3 \\
$34-40$ & 47 & 15.3 \\
$>40$ & & \\
Ethnic Group & 125 & 55.1 \\
Malay & 104 & 20.6 \\
Malaysian Chinese & 34 & 24.3 \\
Indian Malaysia & & \\
Income Level RM & 44 & 14.5 \\
$<2000$ & 97 & 31.9 \\
2001-4000 & 96 & 31.6 \\
4001-6000 & 67 & 22 \\
$>6000$ & & \\
Usage & 156 & 51.3 \\
Weekly & 104 & 34.2 \\
Biweekly & 19 & 8.2 \\
Once in a month & 25 & 6.3 \\
Every three month and above & & \\
Education & 24 & 7.9 \\
A-level and below & 160 & 52.6 \\
Undergraduate & 51 & 22.7 \\
Post Graduate & 69 & \\
Others & & \\
\hline & & \\
\hline
\end{tabular}

$6.3 \%$ of the respondents who use the aforementioned shopping AR apps monthly or every three months, respectively.

\subsection{Model assessment in WarpPLS-SEM}

\subsubsection{Measurement model assessment and psychometric characteristics of the scales}

Convergent and discriminant validities are designed to assess the measurement model (Byrne, 2016; Kock, 2018). To ensure the achievement of convergent validity, the results of composite reliability (CR) and Average Variance Extracted (AVE) need to be scrutinised. As suggested by (Japutra and Molinillo, 2019; Kock, 2018), the convergent validity is accomplished if the indicators of the measurement model meet or exceed the cut-off point of 0.70 . However, indicator loading within the range of $40-70$ might be accepted if by eliminating the item/s, $\mathrm{R}^{2}$ and convergent validity doesn't improve. As presented in Table 2, apart from a few items which are within the range of 40-70, the majority of measurement model items have met the requirement cut-off point of 70, and all the items are loaded within their correspondent constructs. However, items UTB1 from the utilitarian benefit construct, HB1 from the hedonic benefit construct, ARV4 from the AR vividness construct, and RABE1, RABE5, and RABE8 from shopping AR app brand experience were eliminated from the set due to low factor loading (e.g. $<040$ ). As tabulated in Table 2, composite reliability (CR) for all the endogenous and exogenous variables are above 0.70 and, thus, the requirement of measurement models' reliability is achieved.

As indicated in Table 3, the square roots of AVE values are greater than its respective inter-constructs' correlations, showing that discriminant validity is achieved (Kock, 2018). WarpPLS 6.0 is able to calculate the full collinearity for each constructs, therefore permitting the concurrent evaluation of lateral and vertical collinearity between the latent variables (Kock, 2018). Table 2 shows that the full collinearity in all constructs is lower than the recommended cut-off point of 5, which is considers as an appropriate collinearity threshold (Hair et al., 2016; Kock, 2018). Moreover, as outlined in Appendix B, since the loading between the individual constructs across the measurement models 
Table 2

Assessment results of measurement model.

\begin{tabular}{|c|c|c|c|c|c|c|}
\hline Construct & Measurement items sources & Loading & VIF & AVE & C.R & $\alpha$ \\
\hline $\begin{array}{l}\text { Augmented Reality Quality } \\
\text { (ARQ) }\end{array}$ & Adopted from Poushneh (2018) & & 3.303 & 0.722 & 0.948 & 0.947 \\
\hline ARQ1 & This app with augmented reality feature/s on is highly informative & 0.728 & & & & \\
\hline ARQ2 & $\begin{array}{l}\text { This app with augmented reality feature/s on provides relevant information that helps me } \\
\text { with my purchase decision. }\end{array}$ & 0.770 & & & & \\
\hline ARQ3 & $\begin{array}{l}\text { This app with augmented reality feature/s on adds virtual information to places where } \\
\text { belong }\end{array}$ & 0.766 & & & & \\
\hline ARQ4 & This app with augmented reality feature/s on provides reliable information that I need. & 0.794 & & & & \\
\hline ARQ5 & This app with augmented reality feature/s is safe to use & 0.697 & & & & \\
\hline ARQ6 & $\begin{array}{l}\text { This augmented reality app give me the perception like the [OBJECT] was actually there in } \\
\text { the real world }\end{array}$ & 0.757 & & & & \\
\hline ARQ7 & It seemed that everything I saw on the "augmented reality app display" was real. & 0.743 & & & & \\
\hline $\begin{array}{l}\text { Augmented Reality Novelty } \\
\text { (ARN) }\end{array}$ & Adopted from McLean (2018) & & 3.825 & 0.761 & 0.927 & 0.927 \\
\hline ARN1 & Using augmented reality feature offers something new each time. & 0.807 & & & & \\
\hline ARN2 & Using augmented reality application offers unique information. & 0.796 & & & & \\
\hline ARN3 & Using augmented reality feature offers something different each time. & 0.742 & & & & \\
\hline ARN4 & Using augmented reality app offers special content. & 0.750 & & & & \\
\hline $\begin{array}{l}\text { Augmented Reality Interactivity } \\
\text { (ARI) }\end{array}$ & Adopted from McLean (2018) & & 4.021 & 0.712 & 0.955 & 0.955 \\
\hline ARI1 & $\begin{array}{l}\text { I prefer using augmented reality apps that let me decide whether to receive messages from } \\
\text { it. }\end{array}$ & 0.766 & & & & \\
\hline ARI2 & I prefer using augmented reality app that includes two way communications with it. & 0.745 & & & & \\
\hline ARI3 & I prefer using augmented reality app that talks me back. & 0.788 & & & & \\
\hline ARI4 & & 0.758 & & & & \\
\hline ARI5 & I prefer using augmented reality app that makes me feel it wants to listen to me. & 0.788 & & & & \\
\hline ARI6 & I prefer using augmented reality apps that are effective in gathering users' feedback. & 0.753 & & & & \\
\hline ARI7 & I was in control of my navigation through the this augmented reality app & 0.782 & & & & \\
\hline $\begin{array}{l}\text { Augmented Reality } \\
\text { Customisation (ARC) }\end{array}$ & Adopted from Y.-H. Fang (2019) and Smink et al. (2020) & & 3.251 & 0.739 & 0.919 & 0.917 \\
\hline ARC1 & It feels like the augmented reality app is talking to me personally. & 0.770 & & & & \\
\hline ARC2 & It is important to me to feel like the augmented reality app is my personal area when I use it. & 0.791 & & & & \\
\hline ARC3 & $\begin{array}{l}\text { Adding Customised information like (Notification services) to the augmented reality app } \\
\text { attracts my attention. }\end{array}$ & 0.790 & & & & \\
\hline ARC4 & Augmented reality app can offer customised information that may meet my needs. & 0.691 & & & & \\
\hline $\begin{array}{l}\text { Augmented Reality Vividness } \\
\text { (ARV) }\end{array}$ & Adopted from McLean (2018) & & 3.779 & 0.699 & 0.921 & 0.921 \\
\hline ARV1 & The visual display provided through this augmented reality app was clear & 0.716 & & & & \\
\hline ARV2 & The visual display provided through this augmented reality app was detailed & 0.726 & & & & \\
\hline ARV3 & The visual display provided through this augmented reality app was vague (R) & 0.773 & & & & \\
\hline ARV5 & The visual display provided through this augmented reality app was sharp & 0.713 & & & & \\
\hline ARV6 & The visual display provided through this augmented reality app was well-defined & 0.759 & & & & \\
\hline Utilitarian Benefits (UTB) & Rauschnabel et al. (2019) and fang et al. (2017) & & 4.121 & 0.771 & 0.944 & 0.944 \\
\hline UTB2 & I find it easy to get the augmented reality feature/s on the app to do what I want it to do & 0.771 & & & & \\
\hline UTB3 & $\begin{array}{l}\text { The provided feature/s of augmented reality on this app helped me to better evaluate the } \\
\text { products. }\end{array}$ & 0.784 & & & & \\
\hline UTB4 & $\begin{array}{l}\text { Using the augmented reality feature/s on the app enables me to accomplish shopping tasks } \\
\text { more }\end{array}$ & 0.774 & & & & \\
\hline UTB5 & quickly & 0.787 & & & & \\
\hline UTB6 & It is easy for me to become skillful at using the augmented reality feature/s on the app & 0.781 & & & & \\
\hline Hedonic Benefits (HB) & Rauschnabel et al. (2019) and Fan et al. (2017) & & 3.474 & 0.773 & 0.954 & 0.953 \\
\hline HB2 & This app with augmented reality feature/s on is fun. & 0.794 & & & & \\
\hline HB3 & This app with augmented reality feature/s on is a good time killer. & 0.795 & & & & \\
\hline HB4 & This app with augmented reality feature/s on is presentable. & 0.766 & & & & \\
\hline HB5 & This app augmented reality feature/s on is like a treat for me. & 0.808 & & & & \\
\hline HB6 & This app with augmented reality feature/s on improves my mood, makes me happier. & 0.780 & & & & \\
\hline HB7 & This app with augmented reality feature/s on is exciting. & 0.742 & & & & \\
\hline $\begin{array}{l}\text { Retail App Brand Engagement } \\
\text { (RABE) }\end{array}$ & (Fang et al., 2017) & & 2.344 & 0.713 & 0.925 & 0.925 \\
\hline RABE2 & Using augmented reality feature/s stimulates my interest in this retail brand. & 0.736 & & & & \\
\hline RABE3 & Using augmented reality feature makes me thinking about this retail brand. & 0.710 & & & & \\
\hline RABE4 & I think about this retail brand a lot when using the brand's augmented reality app. & 0.759 & & & & \\
\hline RABE6 & I feel positive when I use brand's augmented reality app & 0.779 & & & & \\
\hline RABE7 & I feel good when I use the brand's augmented reality app & 0.744 & & & & \\
\hline Psychological inspiration (PSYI) & Rauschnabel et al. (2019) & & 2.128 & 0.764 & .929 & 0.928 \\
\hline PSYI1 & This app with its added augmented reality feature/s on inspires me in a way. & 0.705 & & & & \\
\hline PSYI2 & The added feature/s of augmented reality on this app stimulates my thinking. & 0.806 & & & & \\
\hline PSYI3 & $\begin{array}{l}\text { The added feature/s of augmented reality on this app gives me new ideas and views on my } \\
\text { purchases. }\end{array}$ & 0.816 & & & & \\
\hline PSYI4 & The added feature/s of augmented reality app improves my retail shopping imagination. & 0.773 & & & & \\
\hline
\end{tabular}


Table 2 (continued)

\begin{tabular}{|c|c|c|c|c|c|c|}
\hline Construct & Measurement items sources & Loading & VIF & AVE & C.R & $\alpha$ \\
\hline $\begin{array}{l}\text { Continuance Intention to Use } \\
\text { the App (CIUA) }\end{array}$ & Y.-H. Fang (2019); (Hur et al., 2017); Tseng and Lee (2018) & & 2.015 & 0.778 & 0.959 & 0.947 \\
\hline CIUA1 & I intend to stay on as a member of this retail app & 0.797 & & & & \\
\hline CIUA2 & I am willing to actively participate in the activities on this retail app. & 0.769 & & & & \\
\hline CIUA3 & I will frequently use this retail app in the future. & 0.826 & & & & \\
\hline CIUA4 & I strongly recommend that others use this retail app & 0.802 & & & & \\
\hline CIUA5 & I will use this retail app on a regular basis in the future & 0.725 & & & & \\
\hline $\begin{array}{l}\text { Willingness to pay a price } \\
\text { premium (WTPP) }\end{array}$ & Nikhashemi, Jebarajakirthy, and Nusair (2019) and Dwivedi et al. (2018) & & 1.738 & 0.732 & 0.932 & 0.891 \\
\hline WTPP1 & I am willing to pay a higher price for products of this retail AR app brand. & 0.717 & & & & \\
\hline WTPP2 & $\begin{array}{l}\text { I would be willing to pay an extra percentage of my bill to this retail brand due to providing } \\
\text { augmented reality feature/s on their shopping app. }\end{array}$ & 0.791 & & & & \\
\hline WTPP3 & $\begin{array}{l}\text { I'm willing to pay more for this retail brand instead of any other brand, due to providing app } \\
\text { with augmented reality feature/s on. }\end{array}$ & 0.761 & & & & \\
\hline
\end{tabular}

Table 3

Correlations and $\sqrt{ }$ AVE of latent construct.

\begin{tabular}{|c|c|c|c|c|c|c|c|c|c|c|c|}
\hline APQ & APN & ARI & ARC & ARV & UTB & $\mathrm{HB}$ & ARBE & PSYI & CIUA & WTPP & \\
\hline APQ & 0.850 & & & & & & & & & & \\
\hline APN & 0.715 & 0.872 & & & & & & & & & \\
\hline ARI & 0.776 & 0.761 & 0.867 & & & & & & & & \\
\hline ARC & 0.694 & 0.747 & 0.772 & 0.860 & & & & & & & \\
\hline ARV & 0.775 & 0.817 & 0.885 & 0.826 & 0.836 & & & & & & \\
\hline UTB & 0.810 & 0.836 & 0.850 & 0.830 & 0.907 & 0.878 & & & & & \\
\hline HB & 0.751 & 0.777 & 0.824 & 0.872 & 0.832 & 0.849 & 0.879 & & & & \\
\hline ARBE & 0.596 & 0.600 & 0.628 & 0.676 & 0.638 & 0.686 & 0.682 & 0.844 & & & \\
\hline PSYI & 0.464 & 0.505 & 0.467 & 0.456 & 0.503 & 0.569 & 0.537 & 0.494 & 0.874 & & \\
\hline CIUA & 0.295 & 0.353 & 0.286 & 0.262 & 0.248 & 0.325 & 0.285 & 0.444 & 0.579 & 0.882 & \\
\hline WTPP & 0.332 & 0.409 & 0.453 & 0.364 & 0.381 & 0.449 & 0.362 & 0.399 & 0.464 & 0.539 & 0.855 \\
\hline
\end{tabular}

Note: Square roots of average variances extracted (AVEs) shown on diagonal.

shows greater values, the required condition for discriminant validity is accomplished.

\subsection{Assessment of structural equation modelling}

As tabulated in Table 4, Warp-PLS provides a comprehensive global model fit index (Kock, 2020b). Moreover, the extended version of the software (Warp-PLS6) also provides Indicator Correlation Matrix Indices (see Table 5) with an additional model fit index which is similar to co-variance based SEM (Kock, 2020b). Tables 4 and 5 present that the requirement of acceptable model fit index for the proposed model is achieved.

\subsection{Hypothesis testing}

To examine the hypothesised relationship between two main criteria, researchers need to consider the significance of the path coefficient (i.e. $\mathrm{P}$ - value) and $\mathrm{R}^{2}$. As suggested by Hair et al. (2016), p-value below the cut-off point of 0.05 and $\mathrm{R}^{2}$ greater than 0.02 confirms the presence of the relationship among variables. However, the required degree of $\mathrm{R}^{2}$ depends on the complexity and context of the study (Nikhashemi et al.,

Table 4

Classical model fit indices.

\begin{tabular}{lll}
\hline Index & Value & Description \\
\hline Average path coefficient (APC) & 0.195 & $\mathrm{P}<.001$ \\
Average $\mathrm{R}^{2}$ (ARS) & 0.499 & $\mathrm{P}<.001$ \\
Average adjusted R2 (AARS) & 0.493 & $\mathrm{P}<.001$ \\
Average block VIF (AVIF) & 3.276 & Acceptable if $\leq 5$, ideally $\leq 3.3$ \\
Average full collinearity VIF (AFVIF) & 3.595 & Acceptable if $\leq 5$, ideally $\leq 3.3$ \\
Tenenhaus GoF (GoF) & 0.644 & Small $\geq 0.1$, medium $\geq 0.25$, \\
& & large $\geq 0.36$ \\
Nonlinear bivariate causality direction & 1.000 & acceptable if $\geq 0.7$ \\
$\quad$ ratio (NLBCDR) & & \\
\hline
\end{tabular}

Table 5

Indicator Correlation Matrix Indices (Additional Model fit Indices).

\begin{tabular}{lll}
\hline Index & Value & Description \\
\hline $\begin{array}{l}\text { Standardized root mean squared residual } \\
\quad \text { (SRMR) }\end{array}$ & 0.048 & Acceptable if $\leq 0.1$ \\
$\begin{array}{l}\text { Standardized mean absolute residual (SMAR) } \\
\text { Standardized threshold difference count ratio } \\
\quad \text { (STDCR) }=0.987\end{array}$ & 0.037 & Acceptable if $\leq 0.1$ \\
$\begin{array}{l}\text { Standardized threshold difference sum ratio } \\
\quad \text { (STDSR) }=0.922,\end{array}$ & 0.1000 & $\begin{array}{l}\text { Acceptable if } \geq 0.7 \\
\text { ideally }=1\end{array}$ \\
\hline
\end{tabular}

2019). As depicted in Fig. 2, the $\mathrm{R}^{2}$ of Utilitarian Benefit, Hedonic Benefit, Augmented Reality App Engagement, Psychological Inspiration, Continuous Intention to Use Retail App and Willingness to Pay Price Premium are significantly above the mentioned values.

As tabulated in Table 6 and depicted in Fig. 2, the findings of the present study unveil that there is a reasonably meaningful relationship between shopping AR app attributes and customers' hedonic as well as utilitarian benefits; ARQ - > UTB $(\beta=0.182, \mathrm{p}<.001$, t-Value, 3.236), ARQ - > HB $(\beta=0.120, \mathrm{p}<.001$, t-Value, 2.103), ARN - $>\mathrm{UTB}(\beta=$ $0.210, \mathrm{p}>.001$, t-Value, 3.790), ARN - $>$ HB $(\beta=0.174, \mathrm{p}<.001$, $\mathrm{t}-$ Value, 3.123), ARV - $>$ UTB ( $\beta=0.406, p<.001$, t-Value, 7.534), ARV $>$ HB $(\beta=0.3 .7, \mathrm{p}<.001$, t-Value, 5.605), ARI - > HB $(\beta=0.281, \mathrm{p}<$ .001 , $\mathrm{t}$-Value, 5.111). However, the findings reveal that the relationship between AR interactivity and utilitarian benefit, ARI - > UTB $(\beta=0.088$, $\mathrm{p}>.05$, t-Value, 1.052), is insignificant.

Further, the structural model outcomes establish that the impact of UTB - > RABE $(\beta=0.321, \mathrm{p}<.001$, t-Value, 5.893) and UTB - > PSYI $(\beta$ $=0.462, \mathrm{p}<.001, \mathrm{t}$-Value, 8.652) is positive and the influence of PSYI $>$ RABE $(\beta=0.152, \mathrm{p}<.001$, t-Value, 2.705) is significant. This finding explicates that UTB has an effect on RABE directly, and indirectly via PSYI. The study also validates that the relationships between HB - > RABE $(\beta=0.295, p<.001$, t-Value, 5.376) and HB - > PSYI $(\beta=0.203$, 


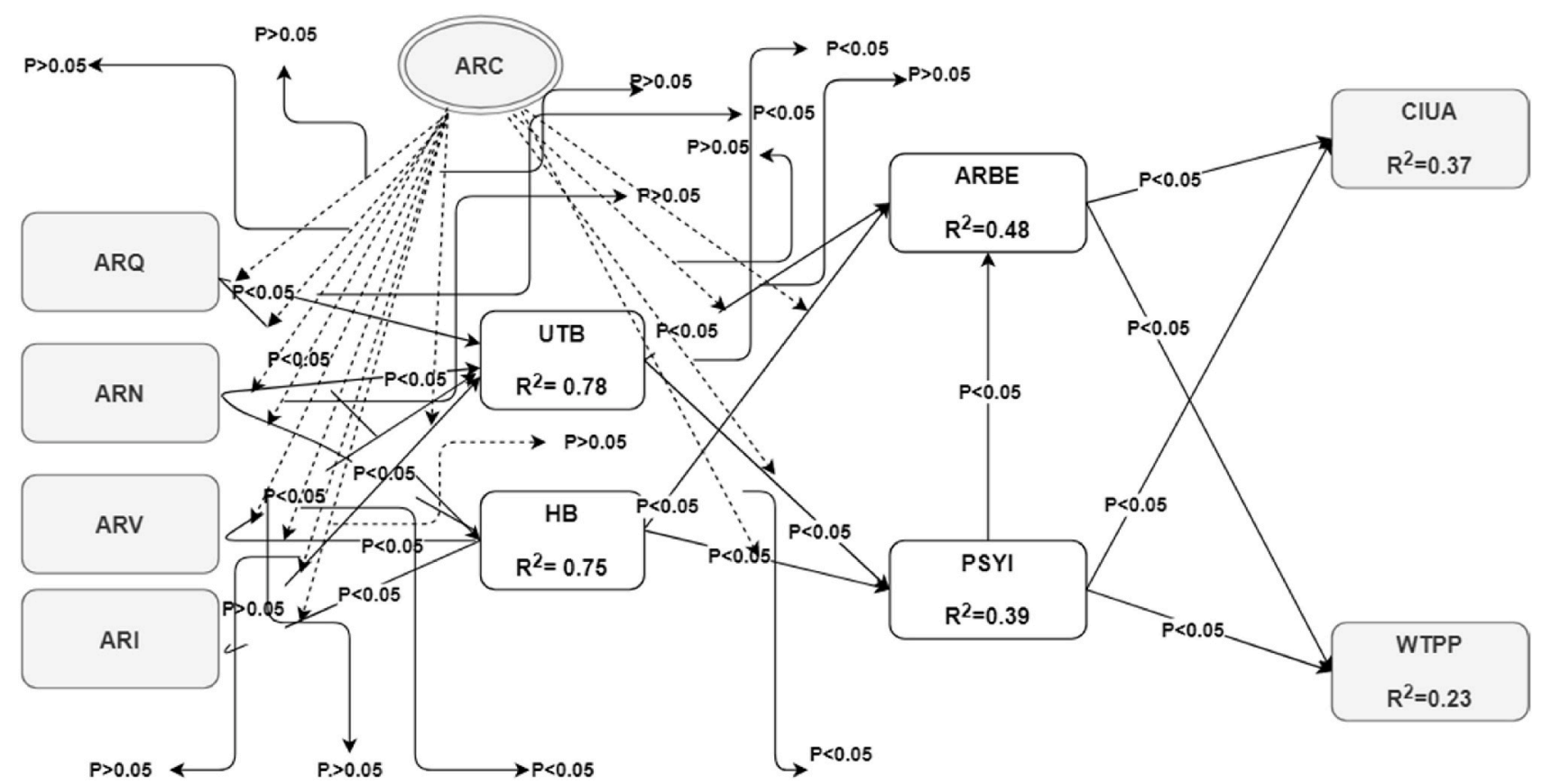

Fig. 2. PLS-SEM results.

Table 6

Structural model outcomes.

\begin{tabular}{lllll}
\hline Hypothesised Path & Path Coefficient Model & p-Value & t- Value & Decision \\
\hline ARQ - > UTB & 0.182 & $<0.001$ & $3.263^{* * *}$ & Supported \\
ARQ - > HB & 0.120 & $<0.001$ & $2.103^{* *}$ & Supported \\
ARN - > UTB & 0.210 & $<0.001$ & $3.790^{* * *}$ & Supported \\
ARN - > HB & 0.174 & $<0.001$ & $3.123^{* * *}$ & Supported \\
ARV - > UTB & 0.406 & $<0.001$ & $7.534^{* * *}$ & Supported \\
ARV - > HB & 0.307 & $<0.001$ & $5.605^{* * *}$ & Supported \\
ARI - > UTB & 0.088 & $>0.05$ & 1.052 & Rejected \\
ARI - > HB & 0.281 & $<0.001$ & $5.111^{* * *}$ & Supported \\
UTB - > RABE & 0.321 & $<0.001$ & $5.893^{* * *}$ & Supported \\
UTB - > PSYI & 0.462 & $<0.001$ & $8.652^{* * *}$ & Supported \\
HB - > RABE & 0.295 & $<0.001$ & $5.376^{* * *}$ & Supported \\
HB - > PSYI & 0.203 & $<0.001$ & $3.655^{* * *}$ & Supported \\
RABE - > CIUA & 0.285 & $<0.001$ & $5.201^{* * *}$ & Supported \\
RABE - > WTPP & 0.215 & $<0.001$ & $3.869^{* * *}$ & Supported \\
PSYI - > RABE & 0.152 & $<0.004$ & $2.705^{* * *}$ & Supported \\
PSYI - > CIUA & 0.424 & $<0.001$ & $7.890^{* * *}$ & Supported \\
PSYI - > WTPP & 0.334 & $<0.001$ & $6.134^{* * *}$ & Supported \\
\hline
\end{tabular}

*t-values: 1.65 (10\%); **t-values: 1.96 (5\%); ***t-values: 2.58 (1\%).

$\mathrm{p}<.001$, t-Value, 3.655) are significant, meaning that, as predicted, hedonic benefit plays a role in enhancing PSYI and RABE in a smart retail setting. Furthermore, this study finds that the relationship between RABE - > CIUA ( $\beta=0.285, \mathrm{p}<.001$, t-Value, 5.201) and RABE $>$ WTPP $(\beta=0.215, \mathrm{p}<.001, \mathrm{t}$-Value, 3.869) is significant. In addition, the influence of PSYI - $>$ CIUA ( $\beta=0.424, p<.001$, t-Value, 7.890) and PSYI - > WTPP $(\beta=0.334, \mathrm{p}<.001$, t-Value, 6.134$)$ are also supported. Therefore, this study establishes the prominent roles of RABE and PSYI in achieving consumer behavioural outcomes related to continuous intention to use retail app and willingness to pay price premium. However, the findings indicate that PSYI plays a more significant role in shaping customer buying behaviours, compared to RABE.

\subsection{Moderating role of $A R$ customisation}

The study identifies that AR customisation moderates the relationship among the variables to some extent. As shown in Table 7 , and Figs. 3-7, AR customisation enhances the relationship between ARN - >
Table 7

WarpPLS- Moderation role of Augmenter reality customisation.

\begin{tabular}{lllll}
\hline $\begin{array}{l}\text { Hypothesised } \\
\text { Path }\end{array}$ & $\begin{array}{l}\text { Path Coefficients/p- } \\
\text { Values }\end{array}$ & $\begin{array}{l}\text { t- } \\
\text { Value }\end{array}$ & Moderated & Decision \\
\hline ARQ - > UTB & $0.016>0.05$ & 0.274 & No & Rejected \\
ARQ - > HB & $0.103>0.05$ & 1.826 & No & Rejected \\
ARN - > UTB & $0.112<0.05$ & 1.980 & Yes & Accepted \\
ARN - > HB & $0.083>0.05$ & 1.472 & No & Rejected \\
ARV - > UTB & $0.099>0.05$ & 1.746 & No & Rejected \\
ARV - > HB & $0.152<0.05$ & 2.718 & Yes & Accepted \\
ARI - > UTB & $0.050>0.05$ & 0.887 & No & Rejected \\
ARI - > HB & $0.051>0.05$ & 0.897 & No & Rejected \\
UTB - > RABE & $0.022>0.05$ & 0.384 & No & Rejected \\
UTB - > PSYI & $0.190<0.05$ & 3.405 & Yes & Accepted \\
HB - > RABE & $0.046>0.05$ & 0.816 & No & Rejected \\
HB - > PSYI & $0.200<0.05$ & 3.598 & Yes & Accepted \\
\hline
\end{tabular}

*t-values: 1.65 (10\%); ${ }^{* *} t$-values: $1.96(5 \%) ;{ }^{* *} t$-values: $2.58(1 \%)$.

UTB (t-value 1.980, $\mathrm{p}<.0 .05$ ), ARV - > UTB (t-value 1.746, $\mathrm{p}<.0 .05$ ), ARV - > HB (t-value 2.718, p < .0.05), UTB - > PSYI (t-value 3.405, $\mathrm{p}<$ .0.05), HB - > PSYI (t-value 3.598, $\mathrm{p}<.0 .05$ ).

However, AR customisation is found not to enhance the association between APQ > UTB (t-value 0.274, p > .0.05); APQ - > HB (t-value 1.526, p <.0.05); ARN - > HB (t-value 1.472, p > .0.05); ARI - > UTB (tvalue $0.887, \mathrm{p}>$.0.05); ARI - > HB (t-value 0.897, $\mathrm{p}>$.0.05); UTB - > RABE (t-value 0.348, $\mathrm{p}>$.0.05) and HB - > RABE (t-value 0.816, $\mathrm{p}>$ $.0 .05)$.

\section{Results of non-linear relationships}

Prior studies emphasise that the nature of associations in behavioural studies tend to be non-linear, whereas in multivariate statistical analysis approaches, the assumption is linear (Kaiser and Messer, 2011; Kock, 2018; Nikhashemi et al., 2019). Applying non-linear variance-based SEM software WarpPLS 6.0, this study scrutinises which proposed relationships are non-linear. To this effect, Warp3 algorithm is applied to identify which relationships are "warped". This algorithm diminishes the occurrence of Simpson's paradox, as well (Kock and Mayfield, 2015).

This analysis yields unexpected results. The findings reveal that even 


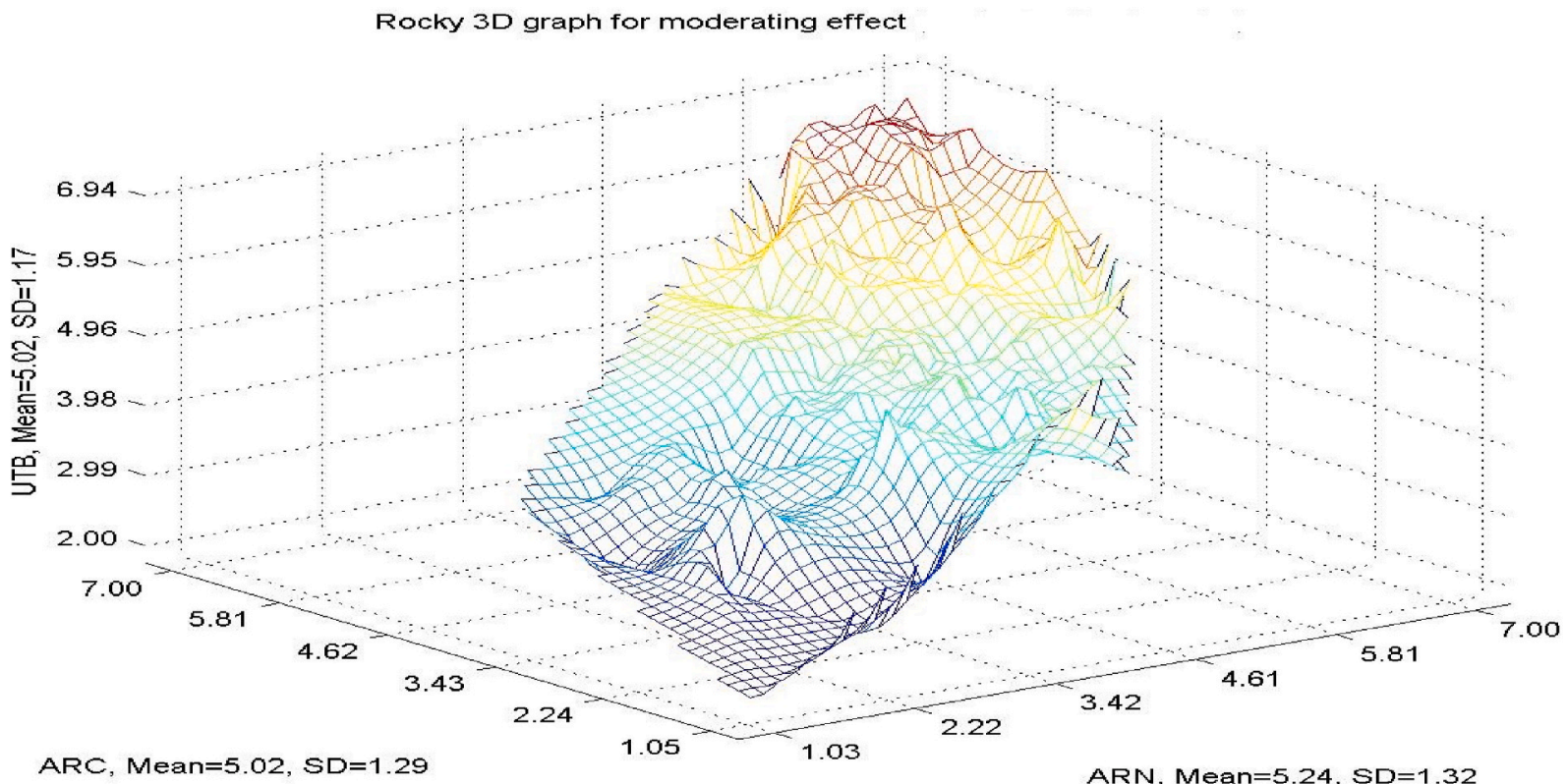

Fig. 3. 3D graph of moderating effect of ARC on relationship between ARN and UTB.

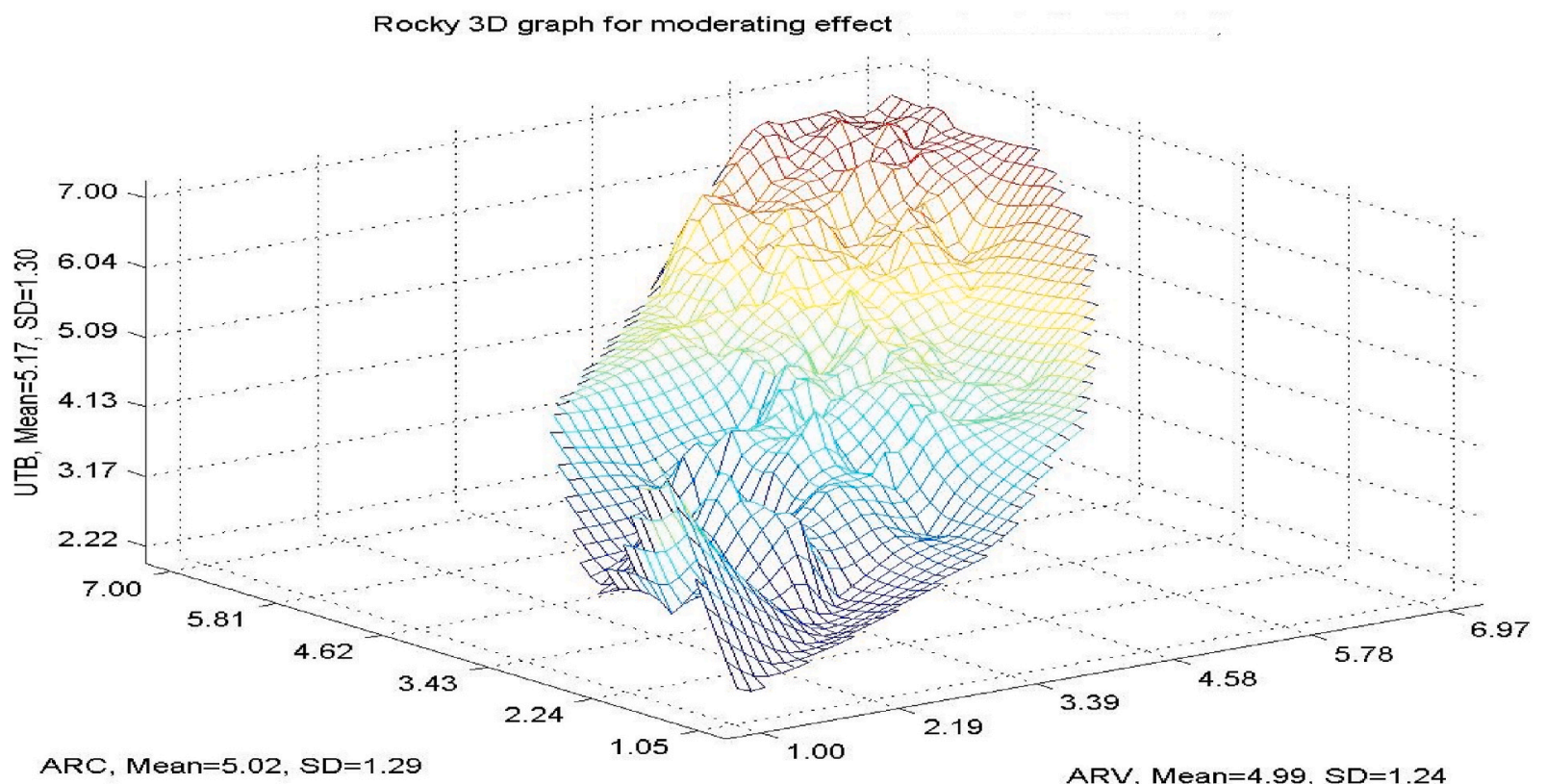

Fig. 4. 3D graph of moderating effect of ARC on relationship between ARV and UTB.

though a linear relationship exists between $\mathrm{UTB} \rightarrow \mathrm{ARBE}, \mathrm{HB} \rightarrow \mathrm{ARBE}$ and $\mathrm{PSYI} \rightarrow$ WTPP, the findings imply that these relationships are, at the same time, non-linear (warped), as is indicated in Fig. 8, Fig. 9 and Fig. 10. Furthermore, prior studies have shown that when the non-linear relationships that best fit the distribution of points are very distorted or very different from being aligned, typically the path coefficient calculated via Warp regression will be higher because they will be reflecting the actual relation (Kock and Hadaya, 2018; Kock and Mayfield, 2015). To illustrate, the non-linear outcomes between UTB $\rightarrow$ ARBE construe that the level of individual engagement towards the shopping AR app engagement is strongly driven by the level of utilitarian benefit gained by customers. Therefore, the relationship might fluctuate due to the level of benefits the customers gain through their consumption benefits.

\section{Discussion and implications}

With the rise of Information Communication Technology, shopping AR apps have assumed an unparalleled role in smart retail settings. Shopping AR apps bridge the gap between the real world and the virtual environment to provide a superior experience and value to the users. Recognising prior studies that have examined AR apps (Fan et al., 2020b; Grzegorczyk et al., 2019; Loureiro et al., 2020; Rauschnabel et al., 2019; van Esch et al., 2019), AR marketing scholars have predominantly focused on the technological aspects and the acceptance (e. g. ease of use, usefulness, convenience, etc.) of AR apps. Attempts to understand the chains of effects from shopping AR app attributes via hedonic and utilitarian benefits toward serial paths of continuous intention to use shopping AR app and willingness to pay price premium 


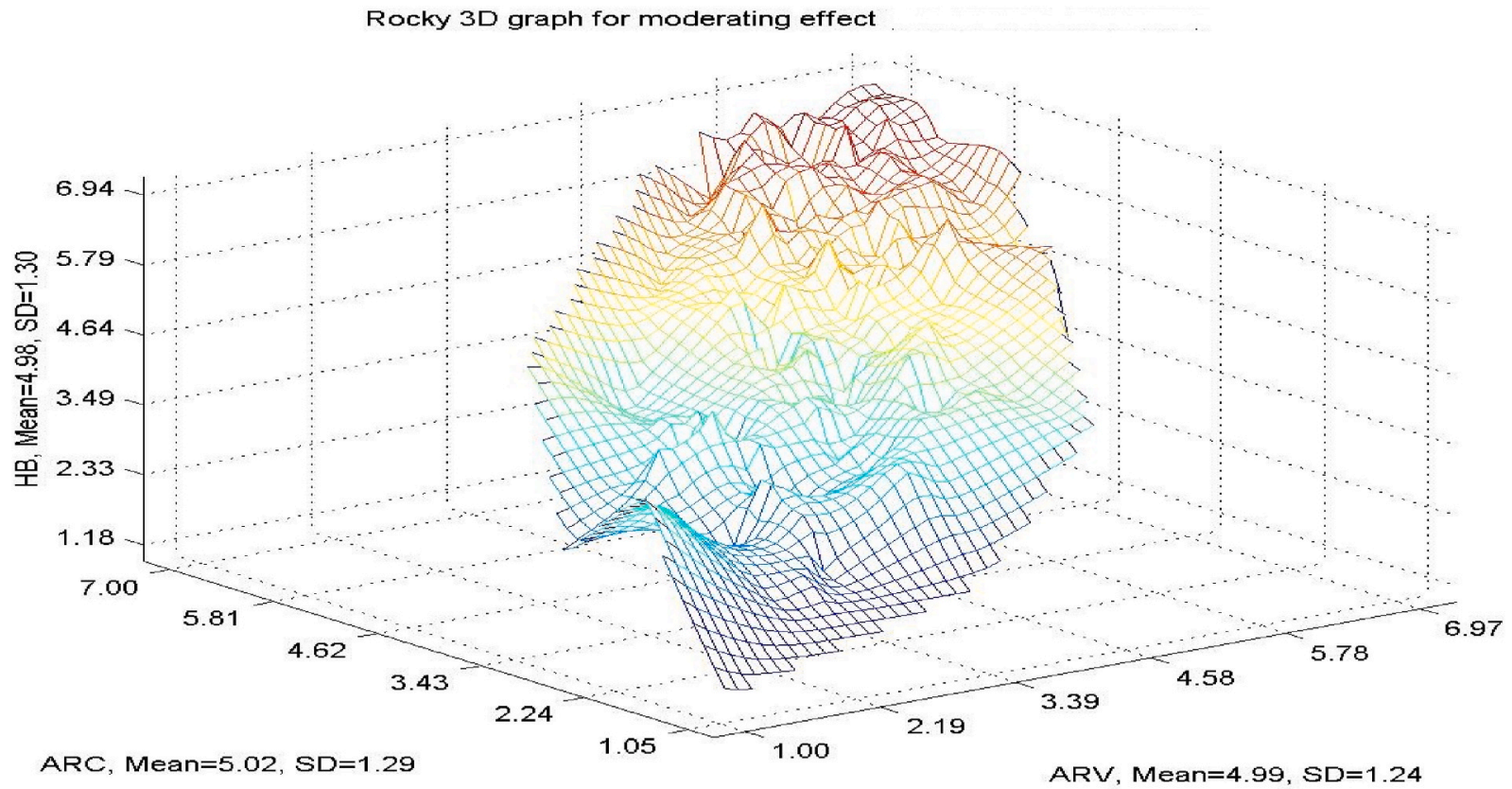

Fig. 5. 3D graph of moderating effect of ARC on relationship between ARV and HB.

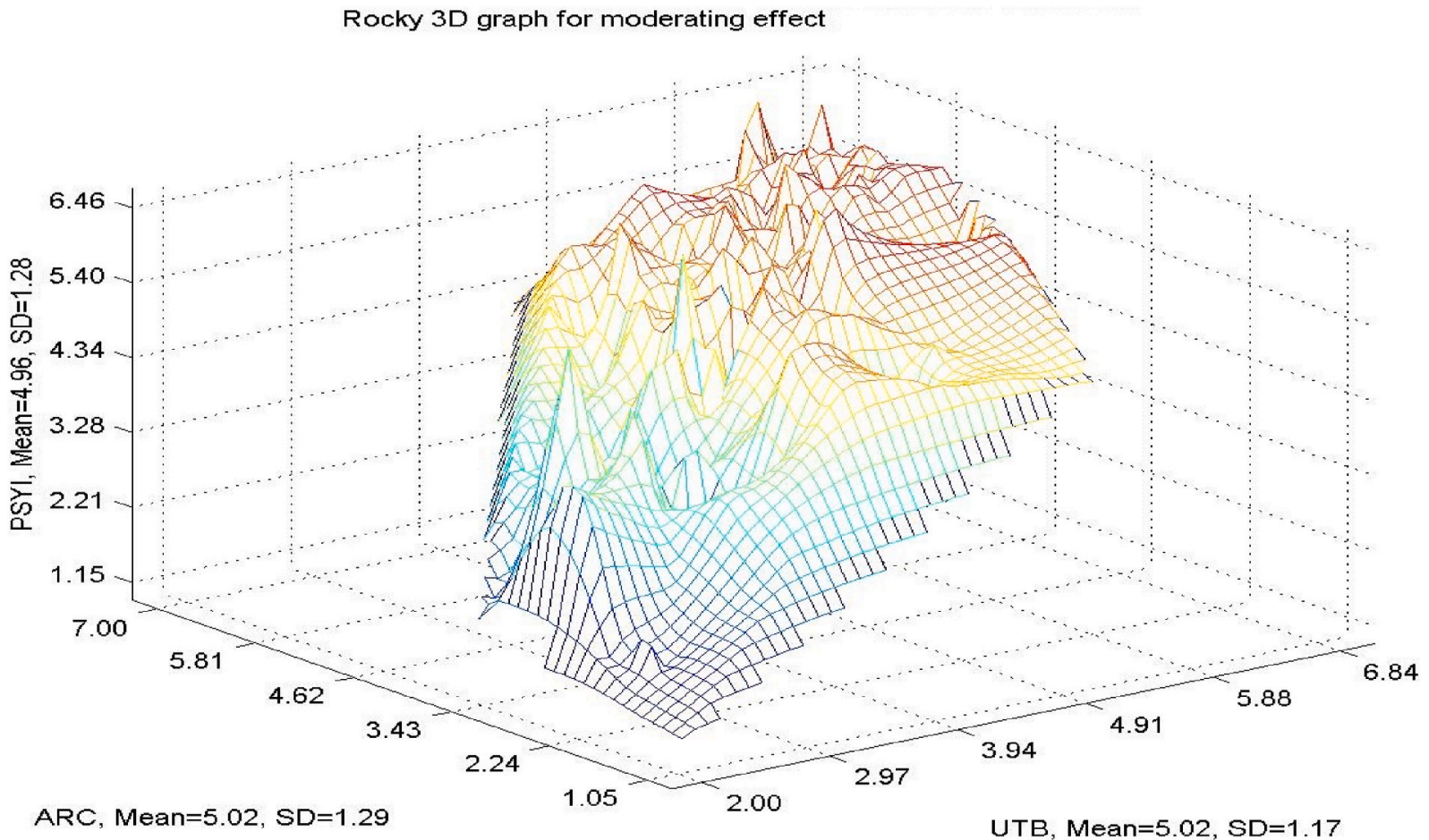

Fig. 6. 3D graph of moderating effect of ARC on relationship between UTB and PSYI.

through the app from customer perspective in a retail context are scarce. Particularly limited are studies that have adopted (a)symmetric perspectives. Therefore, the ultimate goal of the present study is to uncover the causal serial paths towards continuous intention to use a shopping AR app and willingness to pay price premium in retailing context via applying non-linear SEM approach.

Previous research in consumer behaviour has established that a utilitarian benefit, which denotes functionality and a practical nature of the value derived from an experience, and hedonic benefits associated with enjoyment and experiential attributes, constitute important variables in understanding the causal effects between AR enabled mobile technology and cognitive, affective and behavioural brand-related outcomes (Rauschnabel et al., 2019). The results in this study affirm that the hypothesised attributes of shopping AR apps, AR quality, AR vividness and AR novelty, are positively related to the customers' utilitarian and hedonic benefits perceptions. The exception is AR interactivity, which is found not to exhibit a positive relationship with utilitarian benefit. The lack of positive causality between AR interactivity and utilitarian benefit apparently contradicts the findings of McLean and Wilson (2019) who report a positive relationship between 
Smooth 3D graph for moderating effect

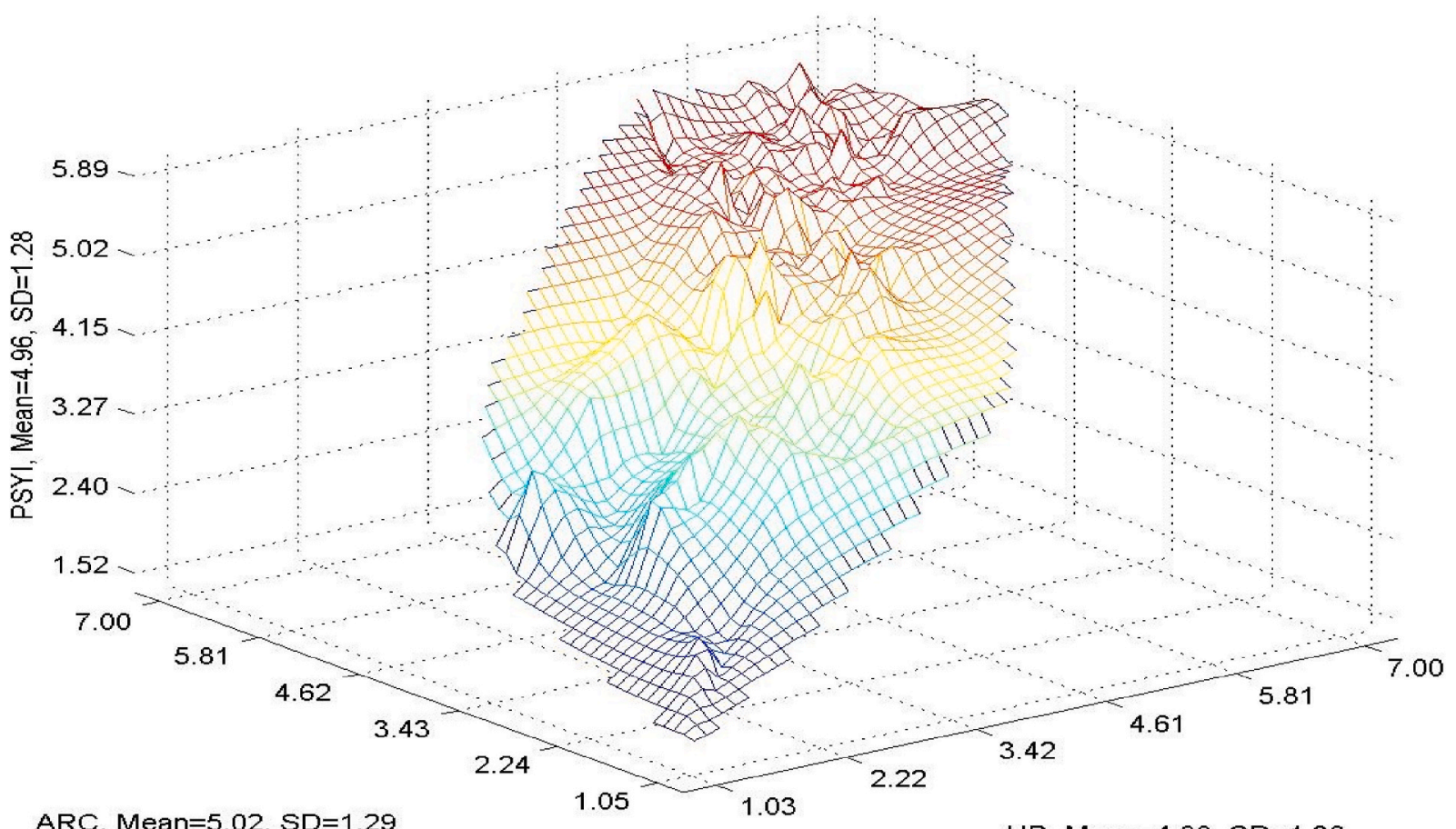

ARC, Mean $=5.02, S D=1.29$

Fig. 7. 3D graph of moderating effect of ARC on relationship between HB and PSYI.

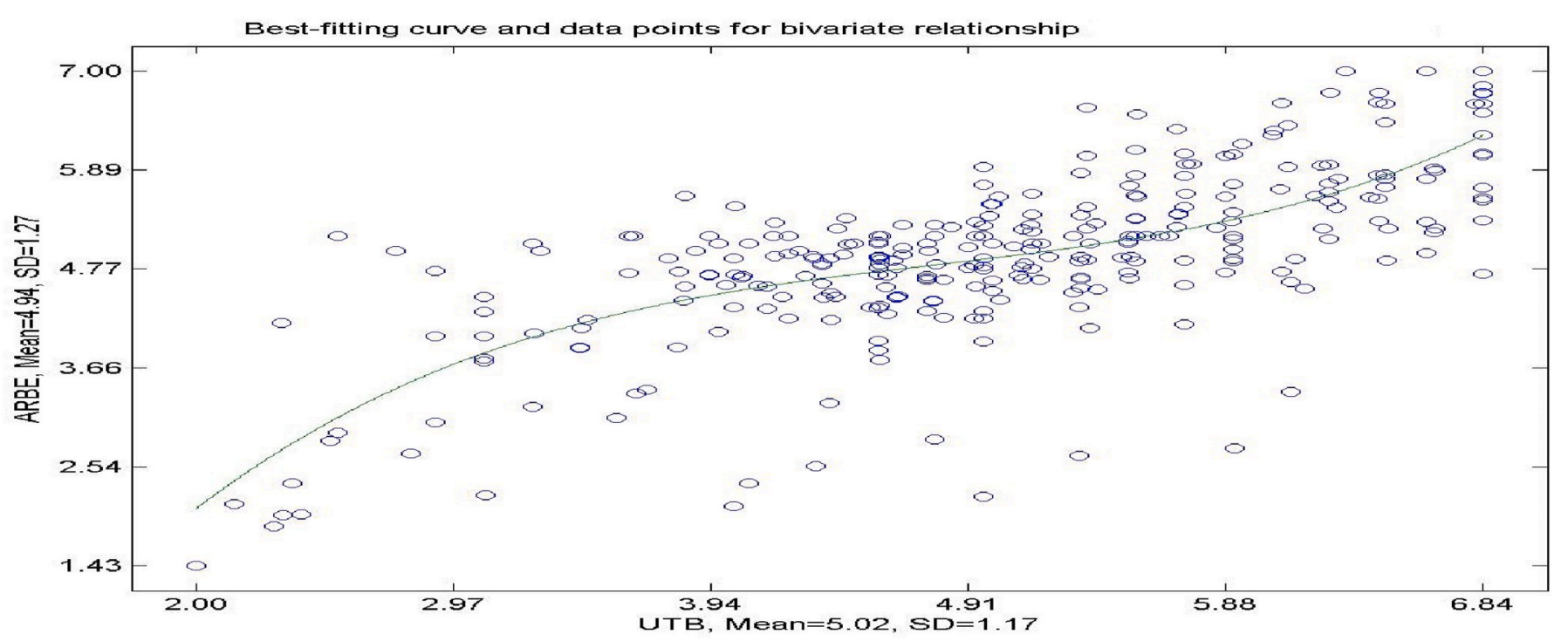

Fig. 8. Nonlinear relationship between UTB and RABE.

interactivity and usefulness. However, Yin et al. (2017) suggest that familiarity with the technology reduces the positive effect of interactivity on customer responses. Building on Yin et al. (2017) stipulation, the findings here indicate that the path from interactivity towards positive brand-related outcomes is constitutive of entertainment and enjoyment derived from the experience, rather than the functional value sought in a shopping experience. It would appear that a repeat use of a shopping AR app reduces the customer's perception of utility facilitated by interaction that is two-way, controllable, and responsive to their actions (Mollen and Wilson, 2010). Notwithstanding, consistent with the views of Böttger et al. (2017), customers nevertheless appreciate these core dimensions of interactivity for the entertainment and enjoyment value, which not only initiates the adoption of the app but stimulates further engagement (Dwivedi et al., 2018; Fang et al., 2017; Verhagen et al., 2015a). This would suggest that from a practical perspective, shopping AR app developers need to ensure that the structural components of shopping AR apps are designed with the view of driving excitement and entertainment, rather than being purely functional.

The results further establish that even though the shopping AR app attributes positively influence utilitarian and hedonic benefits, the effect on utilitarian benefits, with the exception of AR interactivity, are more noticeable. This might be due to the fact that utilitarian benefits are related to functional and practical attributes of a product (Picot-Coupey 


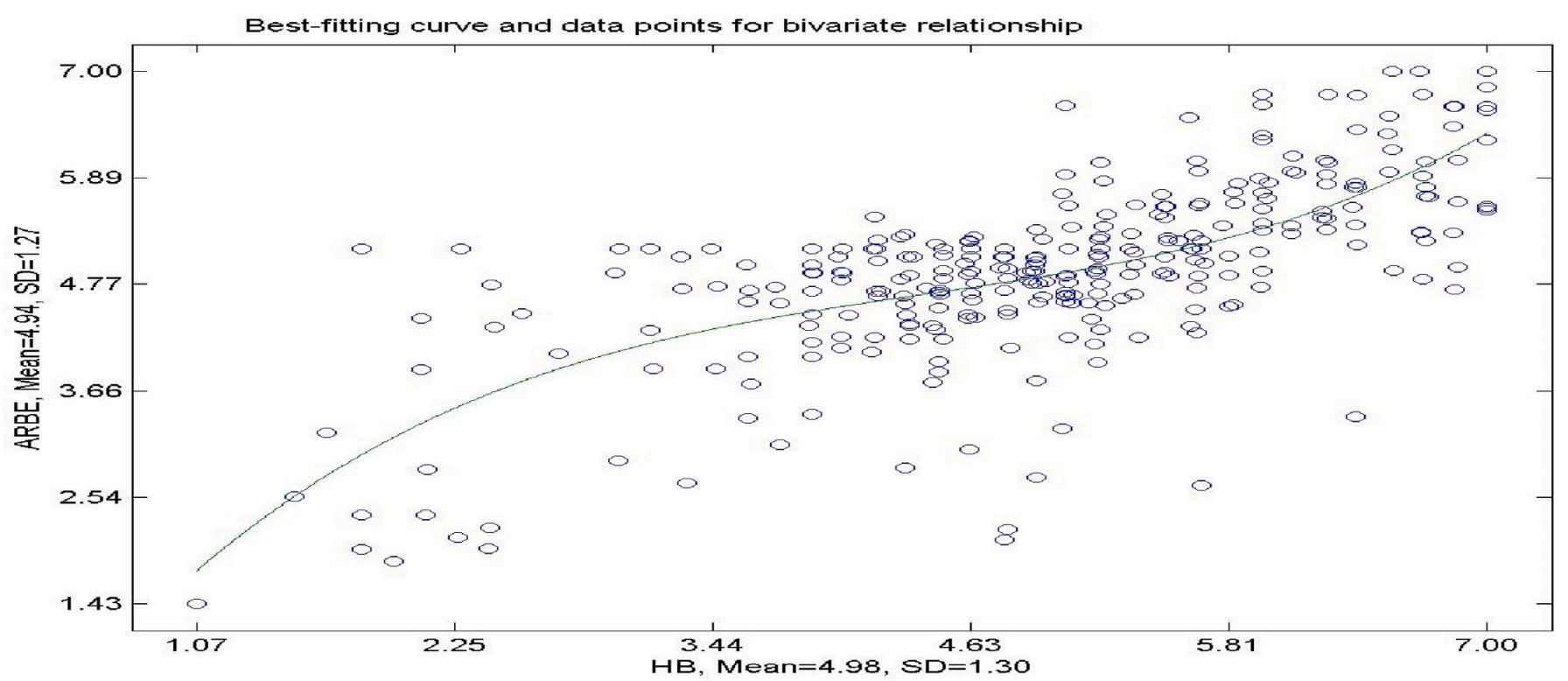

Fig. 9. Nonlinear relationship between $\mathrm{HB}$ and RABE.

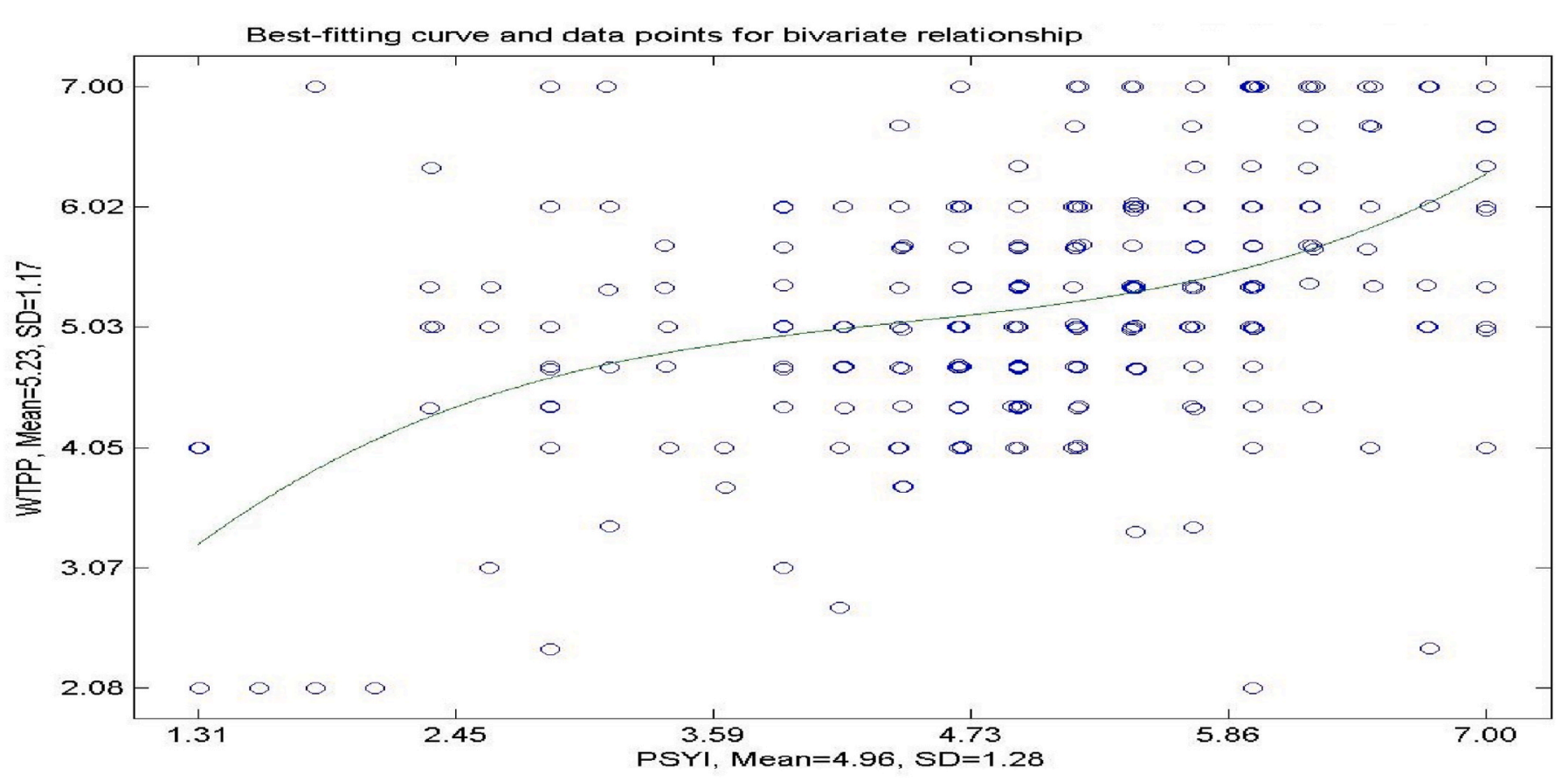

Fig. 10. Nonlinear relationship between PSYI and WTPP.

et al., 2020) that customers seek. Therefore, since shopping AR apps can provide customers all the necessary detailed information regarding the product with which to make a better purchase decision, to include a higher representation of quality image or the ability to try on the product, the functional needs of customers with regard to the product are met and, ultimately, the utilitarian benefit is perceived.

Shopping AR apps that stimulate customers to perceive the control of what they see as generated by the combined real world and virtual environment (i.e. AR interactivity), along with a clear and flawless representations of an image (i.e. AR vividness), unique and distinctly personlisable content (i.e. AR novelty), and detailed information that the customer can rely on (AR quality), have the capacity to establish feelings of excitement, entertainment and enjoyment (hedonic benefit), as well as provide a practical, functional experience (utilitarian benefit).
The unique combination of the values derived from the encounter of telepresence (Mollen and Wilson, 2010) enhances the customer's utilitarian and hedonic perceptions towards the app (van Esch et al., 2019).

Drawing further on the discussion of the relationship between AR attributes and customer benefits, the findings confirm that when users encounter a product virtually in a shopping AR app with which they have no prior familiarity, they encounter an experiential consumption situation. The experience is induced through the capacity of the app to establish an interactive channel that enables the customer to experience online shopping without an actual presence in a brick-and-mortar store (Hilken et al., 2017). The near-realistic shopping experience facilitates an improvement in the functional outcomes for the customer in an online shopping experience. The findings thus validate that shopping AR apps have the capacity to stimulate practical experience entailed in the 
utilitarian benefit accrued. Moreover, the utility derived from the experience is further enhanced by experiential qualities related to aesthetics of the enhanced imagery, enjoyment of the unique content and excitement derived from the unmatched functionality offered through AR's exclusive mechanics triggered through the app.

These findings indicate the emergence of satisfaction within the serial paths of the initial stimuli-organism interactions. As is demonstrated, the performance of the AR app attributes met the expectations of convenience, enjoyment and excitement associated with using the IS. This is consistent with prior studies of Li and Fang (2019) who suggest that utilitarian benefits in the form of perceived usefulness drives satisfaction and Chen et al. (2020) who find that both utilitarian and hedonic benefits, as studied through perceived usefulness and perceived enjoyment, positively affect satisfaction.

The results further unveil that both utilitarian benefits and hedonic benefits accrued by customers through the attributes of shopping AR apps (AR quality, AR novelty, AR vividness, AR interactivity) have a significant effect on shopping AR app engagement (RABE), and on customer's psychological inspiration (PSYI). This is consistent with the findings of Rauschnabel et al. (2019) who report that hedonic and utilitarian benefits can be regarded as customer outcomes related to affective (e.g. psychological inspiration) and behavioural (e.g. shopping AR app engagement, continuous intention to use AR app) constructs. However, in contrast with Rauschnabel et al. (2019), our findings demonstrate that psychological inspiration positively influences customers shopping AR app engagement. One explanation could be drawn from our theorising grounded in UGT and TCT that in terms of the serial paths from attributes to post-adoption behaviour for novel apps, attitude begins to emerge post-initial engagement. Within this perspective, attitude is triggered by the compounded effect of satisfaction emergent at each serial path and is fully developed as habit (Chen et al., 2020; Hsiao et al., 2016) and attachment (Li and Fang, 2019) form, to enable overall positive or negative evaluation of the system to determine continuance intention (Chen et al., 2020).

Besides, the findings establish that customer engagement with shopping AR apps and psychological inspiration are significant predictors of continuous intention to use a shopping AR app and of customers' willingness to pay price premium. Consistent with the views of Böttger et al. (2017), this study shows that customers who feel inspired and engaged with the shopping AR app, as facilitated via experiential experiences, practical benefits, enjoyment and excitement, are more likely to exhibit positive behavioural action, such as continuous intention to use, willingness to pay more, and loyalty, etc. The findings provide further support for previous studies (Fang, 2019; Wang, 2020; Li and Fang, 2019) that those customers whose engagement with a shopping AR app is prompted by the benefits and values accrued tend to enjoy their consumption experience and, thus, they continue to use the app.

We thus extend upon McLean's (2018) conceptualisations grounded in the theory of planned behaviour that engagement with a retailer's shopping AR app influences consumer behaviour. Our results show that following engagement with a retailer's app, positive behavioural consequences in the form of, for example, continuous intention to use shopping augmented reality app, willingness to pay price premium, and loyalty, etc., can be reasonably expected from customers.

Moreover, similar to Rauschnabel et al. (2019), we empirically demonstrate that inspiration is a key construct in continuance usage intention because it has attitudinal consequences for the brand. The findings show that inspiration not only leads to continuance usage but it also enhances engagement with the app. Such strengthening of satisfaction within this loop of serial paths and enhanced positive valence appears to be an important antecedent to the emergence of positive attitude towards the app, as well as towards the brand through spillover effect of positive association (Keller, 2003). Taken together, the attitude then contributes positively to the continuous intention to use the app and the willingness to pay a price premium. Consistent with prior studies discussed above, the findings show that this cycle is repeated until all feedback loops are mitigated.

The study further finds that AR customisation enhances the relationship between AR novelty and utilitarian benefit, AR vividness and utilitarian benefit, utilitarian benefit and shopping AR app engagement, $\mathrm{AR}$ vividness and hedonic benefits, as well as hedonic benefits and psychological inspiration. Accordingly, it is deliberated here that the shopping AR app users perceive a greater degree of hedonic and utilitarian benefits if they are offered the possibility to personalise information, such as audio or visual content. The possibility entailed in AR to allow individual customers to personalise content creates an enhanced sensory experience, as well as greater levels of enjoyment which leads to an increased engagement with the shopping AR app. The study thus concurs with prior research by McLean (2018), Hsiao et al. (2016) and Cheung et al. (2015) that the manifold value derived by customers from engaging with new technology improves customer engagement.

Augmented reality has also been discussed as having a notable role in fostering customer satisfaction, experiential value and brand engagement (McLean, 2018; Park and Yoo, 2020). However, despite the distinctive functions of AR in stimulating a variety of customer cognitive, affective and behavioural responses, the study establishes that AR customisation does not enhance the relationship between AR interactivity and utilitarian benefit. Although inconsistent with prior findings (McLean, 2018), drawing on the discussions related to interactivity involving an individual's subjective perceptions of interactivity (Mollen and Wilson, 2010; Yim et al., 2017) as a motivation determinant (McLean and Wilson, 2019), this incongruity may be a result of the customer's a priori experience of the unique features and characteristics of shopping AR apps. As proposed by Yim et al. (2017), familiarity with the novel features of proficient augmentation and rich sensory environment may result in a diminishing drive related to the particular need satisfaction, and thus the customer may lack the motivation to progress beyond a certain level.

Finally, this study confirms that the relationships of hedonic and utilitarian benefits towards shopping AR app engagement are nonlinear. A further non-linear relationship is identified in the effect of psychological inspiration on customers' willingness to pay price premium. We argue that hedonic and utilitarian benefits perceived by customers generates a positive and non-linear effect on shopping AR app engagement and, also, that psychological inspiration generates a positive non-linear relationship on users/customer's willingness to pay price premium through shopping AR application. In particular, this study identifies that the effect of hedonic and utilitarian benefits on shopping AR app engagement is only significant at the moderate to high level, not at the lower level. The same effect is detected in the relationship between psychological inspiration and user's willingness to pay price premium. As highlighted by Nikhashemi et al. (2019), the nature of the relationships in consumer behaviour studies is most likely to be non-linear.

\subsection{Theoretical implications}

The contribution of the current study is fourfold. First, we extend a comprehensive theoretical model that demonstrates the serial causal paths from a specified set of AR attributes towards continuous intention to use a shopping AR app and customer's willingness to pay price premium via a shopping AR app in a smart retail setting. To the best of the authors' knowledge, this study can be considered as one of the first studies to uncover the chain of effects from mobile shopping AR app attributes to hedonic and utilitarian benefits by incorporating the roles of shopping AR app engagement and psychological inspiration on consumer behavioural consequences. Therefore, the outcomes of the present study add new insights to AR marketing and consumer behaviour literatures by identifying the consequences of shopping AR app use in smart retail contexts. Even though previous studies have highlighted the consequences of AR attributes (McLean, 2018; Park and Yoo, 2020; 
Poushneh, 2018), they focused on the technological aspect of AR, not behavioural and psychological consequences of shopping AR app use in the smart retail setting. For instance, previous studies examined the driving forces of liking or disliking mobile apps (McLean, 2018; Park and Yoo, 2020). Most of these simply build on existing theoretical frameworks related to the original Technology Acceptance Model (Davis, 1989) rather than working on delineating the causal links and mechanisms of the customer-brand relationship facilitated by smart technology. Besides, these studies merely focus on the attitudinal measures as the outcome variables (e.g. reuse intention). In an attempt to progress the field, the present study incorporates shopping AR apps attributes as antecedents (stimuli), hedonic benefits, utilitarian benefits, shopping AR app engagement, and psychological inspiration as a mechanism (organism), and continuous intention to use shopping augmented reality app and customer's willingness to pay price premium as behavioural consequences (response) in an integrated model. Moreover, by building on the TCT (Liao et al., 2009), we begin to explain that although the individual serial paths are interconnected through satisfaction as an outcome of expectation confirmation, post-adoption behavioural outcomes such as continuous intention to use the shopping AR app and willingness to pay a price premium are likely to be influenced by attitudinal change towards the brand. The model provides insights in to the cognitive and affective mechanisms that translate shopping AR app features, characteristics and benefits into managerially relevant outcomes. To this end, the study advances extant knowledge by establishing a series of integrated relationships composed of links between shopping AR app attributes with hedonic and utilitarian benefits, the impacts of hedonic and utilitarian benefits on a customer's psychological inspiration and shopping AR app engagement, a positive effect of a customer's shopping AR app engagement on continuous intention to use and willingness to pay a premium, a direct positive influence of psychological inspiration on continuous intention to use and willingness to pay a premium, as well as indirectly via customer shopping AR app engagement. The results demonstrate that shopping AR app attributes can explain 78 and 75 percent of utilitarian and hedonics' benefits variation, respectively, meaning that these attributes play a critical role in customers' perceptions of utilitarian and hedonic benefits. The significant role of these attributes as cornerstone parts of customers' attitudinal (customer engagement, psychological inspiration) and behavioural consequences are thus substantiated. The study further reveals that the impact of shopping AR app attributes on hedonic and utilitarian benefits is not equally distributed. For instance, the influence of novelty in both utilitarian and hedonic benefits is more noticeable compared to other attributes. The study also provides unique theoretical perspectives that expand our knowledge on the significant contributions of utilitarian and hedonic benefits on shopping AR app engagement and psychological inspirations. The findings show that the effect of utilitarian benefits is more conspicuous, compared to the hedonic benefits variables.

Second, the study incorporates psychological inspiration as one of the emerging constructs in marketing research. Alongside shopping AR app engagement, the impact of psychological inspiration on customers' behavioural consequences (e.g. continuous intention to use shopping AR apps and willingness to pay price premium via a shopping app) is examined. Numerous studies have focused on continuous intention to use an app as a consequence of app engagement and brand attitude (McLean and Wilson, 2019; Park and Yoo, 2020; Esch et al., 2019). However, the impact of shopping AR app engagement and psychological inspiration on other behavioural outcomes such as willingness to pay price premium through shopping AR application have not been investigated in prior studies.

The findings here determine that a customer who is induced to engage with a shopping AR app due to the hedonic and utilitarian benefits is more inclined to pay price premium through the shopping AR app, and to keep continue using the app. More specifically, the study introduces the missing link between shopping AR app engagement and psychological inspiration as the driving forces of customers' willingness to pay a price premium via a shopping AR app. As revealed through the statistical analysis conducted in this study, customer's psychological inspiration caused by the chain effects from AR attributes as well as utilitarian and hedonic benefits, has a significant effect on continuous intention to use the shopping AR app and willingness to pay price premium, rather than shopping AR app engagement. In fact, we find that psychological inspiration positively influences customer AR app engagement. Accordingly, we suggest that psychological inspiration is likely to play a key role in customer engagement and its subsequent effect on post-adoption behavioural outcomes. To this end, this study extends current knowledge by highlighting the influence of a customer's engagement with a shopping AR enabled app and of psychological inspiration on the customer's continuous intention to use the shopping AR app and their willingness to pay price premium via the app.

Third, we incorporate the moderating role of AR customisation in the causal relationships between the shopping AR app attributes and hedonic and utilitarian benefits, as well as its effects on the influence of the accrued utilitarian and hedonic benefits on psychological inspiration and shopping AR app engagement. As indicated by McLean and Wilson (2019), AR customisation may act as a moderator between individual experience with the level of technology (e.g. ease of use, usefulness, etc.) and their behavioural and attitudinal consequences. Nevertheless, until now, this hypothesis remained unexamined and so, the findings of this study advance extant literature by providing empirical proof that AR customisation needs to be considered as a valid moderator of the relationships among the hypothesised variables.

Finally, we offer clarity to the debate in prior literature by offering plausible support for a different treatment of the nature of relationships among some variables with respect to linearity. For instance, the study of Rauschnabel et al. (2019) highlights the importance of the utilitarian and hedonic benefits on consumer behavioural outcomes, but it was unable to show the actual relationship. The findings here clearly demonstrate that the impact of utilitarian and hedonic benefits on shopping AR app engagement is non-linear, meaning that the effects of the aforesaid variables are significant at the moderate to high level of users' perceptions with regard to the benefits gained through hedonic and utilitarian experiences.

\subsection{Practical implications}

In addition to extending extant theoretical knowledge, this study provides practical insights for managers operating in smart retail settings. The findings reveal that AR features play a significant role in shaping the app users' hedonic and utilitarian benefits. It is noteworthy for mangers and app developers to understand the relevant determinants of utilitarian and hedonic benefits in smart retail contexts. As highlighted in consumer behaviour studies, hedonic and utilitarian benefits are the cornerstone parts of customer decision-making processes, as well as attitudinal and behavioural consequences (Martín-Consuegra, and Molina, 2019; Rauschnabel et al., 2019). Therefore, by understanding the extent to which AR features and characteristics can shape a user's behaviour is a crucial task for managers. For instance, AR vividness provides customers a clear and colourful, unique representation of the product in a virtual environment with the aim of providing an aesthetically pleasing and enjoyable experience to influence the customer's cognitive, affective and conative processing (Yim et al., 2017). For instance, the IKEA AR app enables its users to place furniture items in a virtual simulated room. This provides its users a unique and interactive sense of real experience to help the customer to visualise how the item looks in situ, by combining the real and virtual environments displayed on a screen. This set-up helps the customer to make a better purchase decision. Where the app developers and managers combine the real and virtual worlds in a way that facilitates an enhanced sensory experience for the customer, the customer would be more likely to show a positive cognitive, affective and conative response towards the shopping AR app. All of the studied AR attributes have an impact on hedonic and 
utilitarian benefits, with the exception of AR interactivity. However, the study highlights that AR novelty has a greater degree of impact on users compared to the other attributes. Therefore, the key focus for mangers and app developers should be on how to effectively merge the real and virtual environments to trigger a pleasant experience for app users. Besides, the findings further show that the shopping AR app attributes predict better the utilitarian benefits than the hedonic ones. This finding is consistent with previous research (Rauschnabel et al., 2019) which states that utilitarian benefits are more noticeable in mobile shopping apps than hedonic benefits. However, retailers should not underestimate the significant role of hedonic benefits (e.g. enjoyment, experiential related attributes) obtained by AR app users as it is necessary for the initial adoption as well as a stimulus of further engagement with the app (Fang et al., 2017; Verhagen et al., 2015a). The findings of this study confirm that both utilitarian and hedonic benefits equally impact a customer's shopping AR app brand enjoyment and a customer's psychological inspiration, which eventually results in continuous intention to use the shopping AR app and, more importantly, willingness to pay price premium through the shopping AR app.

\subsection{Limitations and future research directions}

This study provides a number of invaluable insights into the serial causal links that drive brand-related outcomes from customer interactions with shopping AR apps. Notwithstanding the contributions as outlined above, the findings and their consequences for theory and practice are inevitable constrained by some limitations. These limitations, together with the unexpected findings outlined in the results, entail a useful platform from which future research can be directed.
First, this study employs non-probability sampling to ensure that the respondents are active users of the specified shopping AR apps. However, as is widely acknowledged in literature, this sampling approach inhibits the generalisability of the findings beyond the sample characteristics presented in this research. Second, the research technique relies on qualitative comparative analysis (QCA) to identify what set of variables results in higher efficiency of continues intention to use AR app and willingness to pay price premium via AR shopping app. Future studies may identify alternative ways to differentiate between the sets of variables. Next, the findings indicate that the relationship between AR interactivity and utilitarian benefit is insignificant which contradicts the study's initial theorising. Future research needs to examine the different aspects of AR interactivity and their influence on the customers' perceived utility derived from shopping AR apps to clarify this unexpected finding.

Finally, the integration of the UGT and TCT into the theoretical framing suggest differences between initial users and more experienced users in terms of the role of satisfaction, habit and attitude. In this study, we focus on a relatively new technology of shopping AR apps. The majority of users are in the early stages of adoption and so it is unfeasible to determine the predictive capacity of each of the constructs proposed by UGT and TCT. Future studies on this emerging technology would likely provide useful insights in this respect.

\section{Acknowledgement}

This work was supported by the College of Economics and Political Science, Sultan Qaboos University, Mucat, Oman [grant number: 3892B/2019/6]

Appendix A. : Sample Size based on the "inverse root square" and "gamma-exponential"

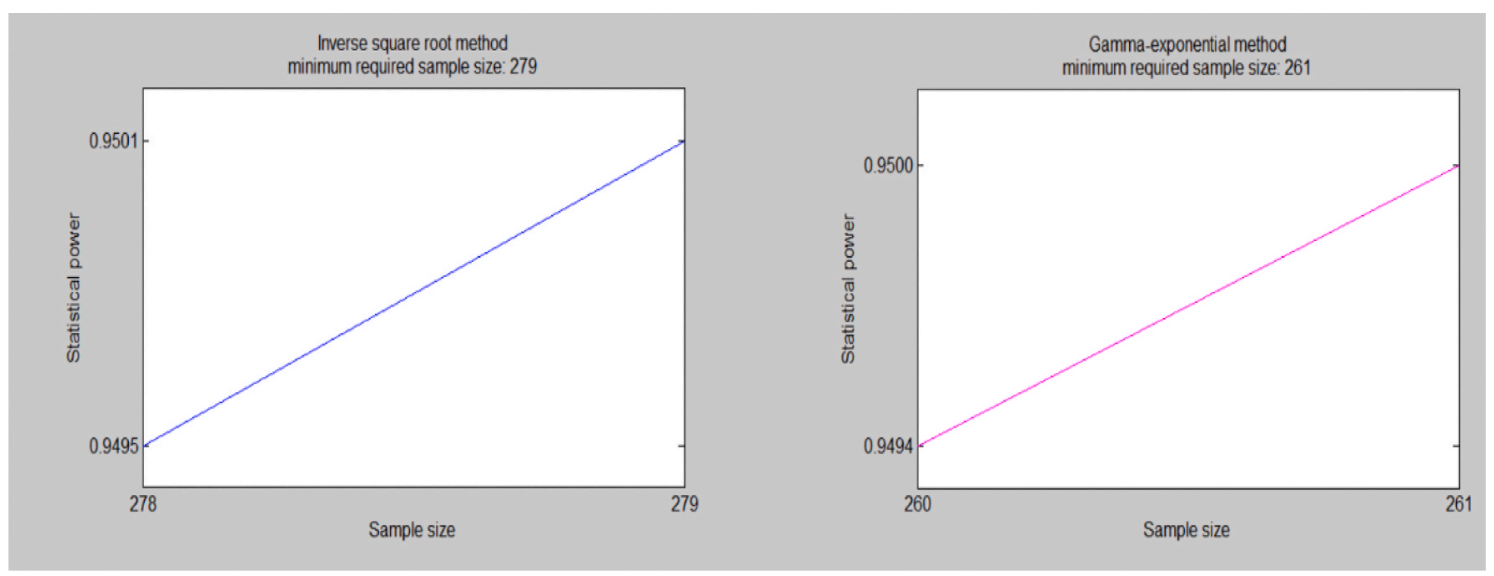

Appendix C. : Example screenshots of the branded AR apps Left: IKEA Place; Right: GAP dressing room 

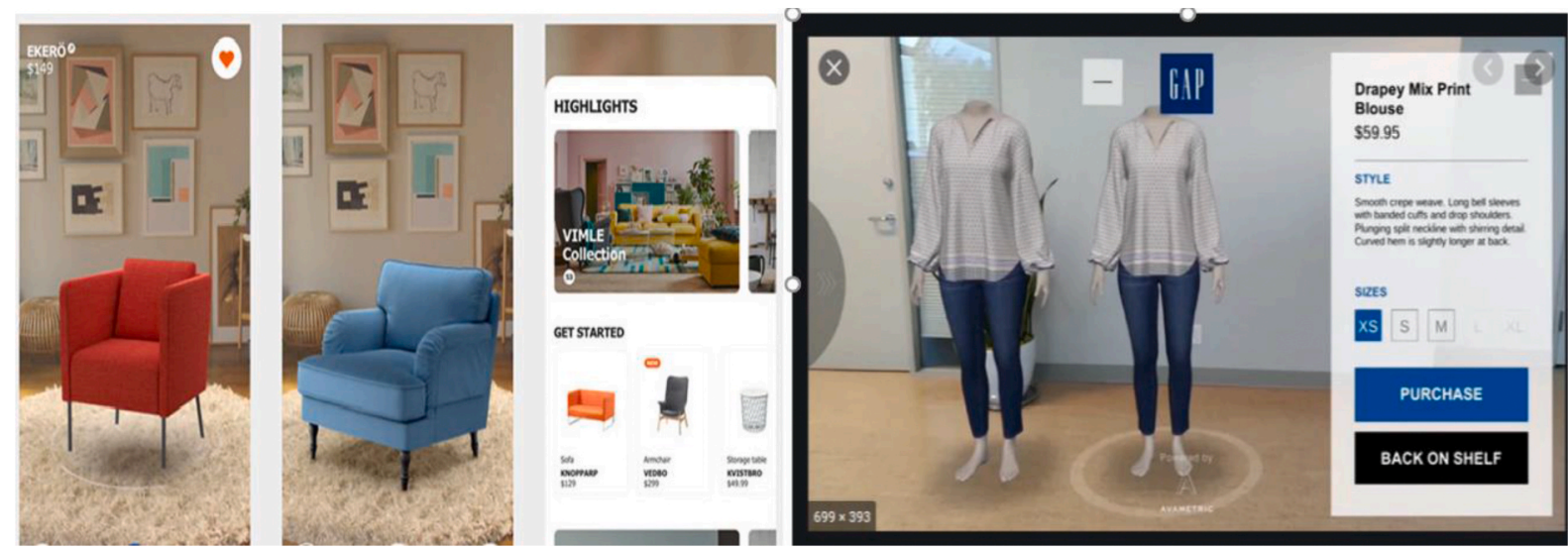

Appendix B: Structure loadings and cross-loadings

\begin{tabular}{|c|c|c|c|c|c|c|c|c|c|c|c|}
\hline & APQ & APN & ARI & ARC & ARV & UTB & HB & ARBE & PSYI & CIUA & WTPP \\
\hline ARQ1 & 0.827 & 0.609 & 0.656 & 0.566 & 0.638 & 0.683 & 0.625 & 0.447 & 0.385 & 0.276 & 0.317 \\
\hline ARQ2 & 0.868 & 0.642 & 0.671 & 0.596 & 0.663 & 0.700 & 0.641 & 0.517 & 0.411 & 0.324 & 0.356 \\
\hline ARQ3 & 0.864 & 0.602 & 0.656 & 0.591 & 0.657 & 0.682 & 0.630 & 0.481 & 0.399 & 0.238 & 0.260 \\
\hline ARQ4 & 0.892 & 0.616 & 0.658 & 0.588 & 0.646 & 0.683 & 0.620 & 0.510 & 0.408 & 0.284 & 0.322 \\
\hline ARQ5 & 0.797 & 0.544 & 0.557 & 0.515 & 0.572 & 0.591 & 0.568 & 0.432 & 0.333 & 0.220 & 0.214 \\
\hline ARQ6 & 0.856 & 0.597 & 0.660 & 0.577 & 0.659 & 0.684 & 0.633 & 0.483 & 0.416 & 0.236 & 0.287 \\
\hline ARQ7 & 0.842 & 0.635 & 0.707 & 0.617 & 0.690 & 0.728 & 0.663 & 0.517 & 0.403 & 0.268 & 0.328 \\
\hline ARN1 & 0.637 & 0.804 & 0.668 & 0.674 & 0.714 & 0.730 & 0.693 & 0.531 & 0.413 & 0.302 & 0.329 \\
\hline ARN2 & 0.634 & 0.854 & 0.666 & 0.648 & 0.701 & 0.728 & 0.682 & 0.525 & 0.458 & 0.354 & 0.369 \\
\hline ARN3 & 0.619 & 0.841 & 0.692 & 0.617 & 0.728 & 0.729 & 0.645 & 0.497 & 0.422 & 0.301 & 0.363 \\
\hline ARN4 & 0.622 & 0.848 & 0.653 & 0.624 & 0.717 & 0.713 & 0.657 & 0.467 & 0.403 & 0.243 & 0.334 \\
\hline ARI1 & 0.692 & 0.677 & 0.864 & 0.663 & 0.769 & 0.749 & 0.705 & 0.532 & 0.433 & 0.261 & 0.404 \\
\hline ARI2 & 0.652 & 0.612 & 0.843 & 0.621 & 0.722 & 0.692 & 0.679 & 0.552 & 0.373 & 0.265 & 0.354 \\
\hline ARI3 & 0.685 & 0.641 & 0.836 & 0.652 & 0.754 & 0.705 & 0.684 & 0.520 & 0.387 & 0.259 & 0.376 \\
\hline ARI4 & 0.654 & 0.690 & 0.850 & 0.613 & 0.783 & 0.753 & 0.727 & 0.528 & 0.388 & 0.219 & 0.347 \\
\hline ARI5 & 0.691 & 0.697 & 0.886 & 0.682 & 0.795 & 0.771 & 0.718 & 0.556 & 0.370 & 0.276 & 0.442 \\
\hline ARI6 & 0.644 & 0.644 & 0.851 & 0.642 & 0.720 & 0.692 & 0.666 & 0.480 & 0.368 & 0.261 & 0.398 \\
\hline ARI7 & 0.672 & 0.655 & 0.880 & 0.662 & 0.767 & 0.735 & 0.717 & 0.542 & 0.372 & 0.244 & 0.378 \\
\hline ARC1 & 0.627 & 0.670 & 0.694 & 0.868 & 0.636 & 0.763 & 0.753 & 0.580 & 0.378 & 0.238 & 0.320 \\
\hline ARC2 & 0.582 & 0.645 & 0.665 & 0.889 & 0.710 & 0.697 & 0.771 & 0.582 & 0.379 & 0.237 & 0.348 \\
\hline ARC3 & 0.605 & 0.633 & 0.648 & 0.888 & 0.611 & 0.705 & 0.761 & 0.551 & 0.360 & 0.179 & 0.293 \\
\hline ARC4 & 0.659 & 0.680 & 0.704 & 0.790 & 0.644 & 0.772 & 0.726 & 0.557 & 0.393 & 0.265 & 0.283 \\
\hline ARV1 & 0.673 & 0.644 & 0.756 & 0.615 & 0.815 & 0.615 & 0.666 & 0.486 & 0.406 & 0.175 & 0.329 \\
\hline ARV2 & 0.641 & 0.640 & 0.744 & 0.622 & 0.824 & 0.714 & 0.658 & 0.459 & 0.346 & 0.181 & 0.293 \\
\hline ARV3 & 0.668 & 0.698 & 0.774 & 0.677 & 0.871 & 0.753 & 0.667 & 0.501 & 0.384 & 0.191 & 0.340 \\
\hline ARV5 & 0.647 & 0.699 & 0.708 & 0.716 & 0.812 & 0.667 & 0.713 & 0.560 & 0.431 & 0.234 & 0.308 \\
\hline ARV6 & 0.671 & 0.739 & 0.747 & 0.783 & 0.857 & 0.624 & 0.767 & 0.600 & 0.437 & 0.262 & 0.321 \\
\hline UTB2 & 0.752 & 0.754 & 0.761 & 0.720 & 0.600 & 0.869 & 0.646 & 0.606 & 0.484 & 0.266 & 0.366 \\
\hline UTB3 & 0.734 & 0.746 & 0.760 & 0.728 & 0.821 & 0.886 & 0.763 & 0.578 & 0.483 & 0.268 & 0.340 \\
\hline UTB4 & 0.710 & 0.713 & 0.745 & 0.715 & 0.782 & 0.872 & 0.603 & 0.565 & 0.439 & 0.257 & 0.379 \\
\hline UTB5 & 0.719 & 0.718 & 0.746 & 0.736 & 0.788 & 0.885 & 0.640 & 0.595 & 0.481 & 0.291 & 0.423 \\
\hline UTB6 & 0.712 & 0.767 & 0.782 & 0.743 & 0.805 & 0.879 & 0.769 & 0.619 & 0.490 & 0.308 & 0.399 \\
\hline HB2 & 0.670 & 0.687 & 0.723 & 0.771 & 0.724 & 0.742 & 0.892 & 0.595 & 0.444 & 0.228 & 0.293 \\
\hline HB3 & 0.660 & 0.698 & 0.717 & 0.782 & 0.732 & 0.736 & 0.892 & 0.573 & 0.452 & 0.263 & 0.331 \\
\hline HB4 & 0.676 & 0.680 & 0.732 & 0.758 & 0.756 & 0.744 & 0.864 & 0.577 & 0.468 & 0.253 & 0.329 \\
\hline HB5 & 0.691 & 0.714 & 0.762 & 0.784 & 0.753 & 0.774 & 0.806 & 0.595 & 0.442 & 0.223 & 0.315 \\
\hline HB6 & 0.707 & 0.715 & 0.777 & 0.754 & 0.761 & 0.766 & 0.878 & 0.589 & 0.458 & 0.267 & 0.371 \\
\hline HB7 & 0.670 & 0.656 & 0.728 & 0.757 & 0.731 & 0.739 & 0.841 & 0.578 & 0.404 & 0.215 & 0.280 \\
\hline RBE2 & 0.479 & 0.488 & 0.488 & 0.530 & 0.493 & 0.518 & 0.538 & 0.835 & 0.413 & 0.375 & 0.326 \\
\hline RBE3 & 0.435 & 0.456 & 0.452 & 0.511 & 0.468 & 0.475 & 0.492 & 0.809 & 0.361 & 0.314 & 0.280 \\
\hline RBE4 & 0.509 & 0.495 & 0.514 & 0.578 & 0.526 & 0.562 & 0.592 & 0.857 & 0.414 & 0.362 & 0.242 \\
\hline RBE6 & 0.579 & 0.581 & 0.609 & 0.653 & 0.625 & 0.671 & 0.651 & 0.877 & 0.404 & 0.361 & 0.345 \\
\hline RBE7 & 0.606 & 0.608 & 0.652 & 0.680 & 0.657 & 0.704 & 0.664 & 0.842 & 0.420 & 0.376 & 0.395 \\
\hline PSYI1 & 0.378 & 0.423 & 0.385 & 0.404 & 0.439 & 0.501 & 0.474 & 0.442 & 0.805 & 0.445 & 0.369 \\
\hline PSYI2 & 0.427 & 0.503 & 0.441 & 0.444 & 0.471 & 0.539 & 0.517 & 0.455 & 0.903 & 0.500 & 0.396 \\
\hline PSYI3 & 0.438 & 0.472 & 0.436 & 0.434 & 0.479 & 0.531 & 0.505 & 0.454 & 0.913 & 0.513 & 0.402 \\
\hline PSYI4 & 0.403 & 0.458 & 0.466 & 0.434 & 0.495 & 0.537 & 0.500 & 0.464 & 0.871 & 0.527 & 0.450 \\
\hline CIUA1 & 0.246 & 0.305 & 0.249 & 0.247 & 0.232 & 0.305 & 0.280 & 0.436 & 0.563 & 0.894 & 0.472 \\
\hline CIUA2 & 0.294 & 0.346 & 0.284 & 0.270 & 0.267 & 0.333 & 0.306 & 0.390 & 0.537 & 0.868 & 0.477 \\
\hline CIUA3 & 0.253 & 0.324 & 0.255 & 0.220 & 0.232 & 0.287 & 0.255 & 0.422 & 0.519 & 0.923 & 0.470 \\
\hline CIUA4 & 0.234 & 0.302 & 0.227 & 0.237 & 0.205 & 0.300 & 0.247 & 0.404 & 0.507 & 0.900 & 0.483 \\
\hline
\end{tabular}


(continued)

\begin{tabular}{|c|c|c|c|c|c|c|c|c|c|c|c|}
\hline & APQ & APN & ARI & ARC & ARV & UTB & HB & ARBE & PSYI & CIUA & WTPP \\
\hline CIUA5 & 0.249 & 0.297 & 0.249 & 0.228 & 0.222 & 0.302 & 0.233 & 0.386 & 0.463 & 0.824 & 0.490 \\
\hline WTPP1 & 0.257 & 0.354 & 0.369 & 0.300 & 0.303 & 0.351 & 0.289 & 0.336 & 0.413 & 0.489 & 0.816 \\
\hline WTPP2 & 0.267 & 0.367 & 0.410 & 0.319 & 0.350 & 0.413 & 0.319 & 0.369 & 0.414 & 0.461 & 0.889 \\
\hline WTPP3 & 0.286 & 0.343 & 0.397 & 0.327 & 0.328 & 0.408 & 0.320 & 0.373 & 0.401 & 0.456 & 0.860 \\
\hline
\end{tabular}

\section{References}

Ajzen, I., 1985. From intentions to actions: a theory of planned behavior. In: Kuhl, J., Beckman, J. (Eds.), Action-control: from Cognition to Behavior. Springer, Heidelberg, Germany, pp. 11-39.

Bagozzi, R.P., 1986. Principles of Marketing Management. Science Research Associates, Chicago, USA.

Bertele, K., Feiereisen, Storey, C., Laer, T.V., 2020. It 's not what you say , it 's the way you say it ! Effective message styles for promoting innovative new services. J. Bus. Res. 107, 38-49.

Böttger, T., Rudolph, T., Evanschitzky, H., Pfrang, T., 2017. Customer inspiration: conceptualization, scale development, and validation. J. Market. 81 (6), 116-131.

Byrne, B.M., 2016. Structural Equation Modeling with AMOS: Basic Concepts, Applications, and Programming, third ed. Routledge, New York.

Chen, C., Hsiao, K.L., Li, W.C., 2020. Exploring the determinants of usage continuance willingness for location-based apps: a case study of bicycle-based exercise apps. J. Retailing Consum. Serv. 55.

Chen, X., Huang, Q., Davison, R.M., 2017. The role of website quality and social capital in building buyers' loyalty. Int. J. Inf. Manag. 37 (1), 1563-1574.

Cheung, C.M.K., Shen, X.-L., Lee, Z.W.Y., Chan, T.K.H., 2015. Promoting sales of online games through customer engagement. Electron. Commer. Res. Appl. 14 (4), 241-250.

Clement, J., 2019. Mobile Apps that Have Been Used Only once 2019 Statista.

Dacko, S.G., 2017. Enabling smart retail settings via mobile augmented reality shopping apps. Technol. Forecast. Soc. Change 124, 243-256.

Davis, F.D., 1989. Perceived usefulness, perceived ease of use, and user acceptance of information technology. MIS Q.: Manag. Inf. Syst. 13 (3), 319-339.

Dwivedi, A., Nayeem, T., Murshed, F., 2018. Brand experience and consumers' willingness-to-pay (WTP) a price premium: mediating role of brand credibility and perceived uniqueness. J. Retailing Consum. Serv. 44, 100-107.

Fan, X., Chai, Z., Deng, N., Dong, X., 2020. Adoption of augmented reality in online retailing and consumers' product attitude: a cognitive perspective. J. Retailing Consum. Serv. 53, 101986-101986.

Fang, J., Zhao, Z., Wen, C., Wang, R., 2017. Design and performance attributes driving mobile travel application engagement. Int. J. Inf. Manag. 37 (4), 269-283.

Fang, Y.-H., 2019. An app a day keeps a customer connected: explicating loyalty to brands and branded applications through the lens of affordance and servicedominant logic. Inf. Manag. 56 (3), 377-391.

Feng, Y., Mueller, B., 2019. The state of augmented reality advertising around the globe: a multi-cultural content analysis. J. Promot. Manag. 25 (4), 453-475.

Grzegorczyk, T., Sliwinski, R., Kaczmarek, J., 2019. Attractiveness of augmented reality to consumers. Technol. Anal. Strat. Manag. 31 (11), 1257-1269.

Hair Jr., J.F., Hult, G.T.M., Ringle, C., Sarstedt, M., 2016. A Primer on Partial Least Squares Structural Equation Modeling (PLS-SEM). Sage Publications.

Hilken, T., de Ruyter, K., Chylinski, M., Mahr, D., Keeling, D.I., 2017. Augmenting the eye of the beholder: exploring the strategic potential of augmented reality to enhance online service experiences. J. Acad. Market. Sci. 45 (6), 884-905.

Hsiao, C.-H., Chang, J.-J., Tang, K.-Y., 2016. Exploring the influential factors in continuance usage of mobile social Apps: satisfaction, habit, and customer value perspectives. Telematics Inf. 33 (2), 342-355.

Huang, T.L., Liao, S., 2015. A model of acceptance of augmented-reality interactive technology: the moderating role of cognitive innovativeness. Electron. Commer. Res. 15 (2), 269-295.

Hur, H.J., Lee, H.K., Choo, H.J., 2017. Understanding usage intention in innovative mobile app service: comparison between millennial and mature consumers. Comput. Hum. Behav. 73, 353-361.

Japutra, A., Molinillo, S., 2019. Responsible and active brand personality: on the relationships with brand experience and key relationship constructs. J. Bus. Res. 99, 464-471.

Javornik, A., 2016a. Augmented reality: research agenda for studying the impact of its media characteristics on consumer behaviour. J. Retailing Consum. Serv. 30, 252-261.

Javornik, A., 2016b. 'It's an illusion, but it looks real!' Consumer affective, cognitive and behavioural responses to augmented reality applications. J. Market. Manag. 32 (9-10), 987-1011.

KPMG, 2018. Tapping into smart retail: a survey of CEOs and consumers in the greater bay area. Retrieved from KPMG webside: https://assets.kpmg/content/dam/kpmg/ cn/pdf/en/2018/11/tapping-into-smart-retail.pdf.

Kaiser, H.M., Messer, K.D., 2011. Mathematical Programming for Agricultural, Environmental and Resource Economics. John Wiley and Sons, Inc, New York.

Keller, K.L., 2003. Brand synthesis: the multidimensionality of brand knowledge. J. Consum. Res. 29 (4), 595-600.

Kim, H.C., Hyun, M.Y., 2016. Predicting the use of smartphone-based Augmented Reality (AR): does telepresence really help? Comput. Hum. Behav. 59, 28-38.
Kim, J., Forsythe, S., 2008. Adoption of Virtual Try-on technology for online apparel shopping. J. Interact. Market. 22 (2), 45-59.

Kock, N., 2020a. Common method bias: a full collinearity assessment method for PLSSEM. In: Latan, H., Noonan, R. (Eds.), Partial Least Squares Path Modeling: Basic Concepts, Methodological Issues and Applications. Springer International Publishing, Cham, pp. 245-257.

Kock, N., 2020b. WarpPLS৫ User Manual:Version 7.0. USA: Laredo, Texas, USA.

Kock, N., Hadaya, P., 2018. Minimum sample size estimation in PLS-SEM: the inverse square root and gamma-exponential methods. Inf. Syst. J. 28 (1), 227-261.

Kock, N., Mayfield, M., 2015. PLS-based SEM algorithms: the good neighbor assumption, collinearity, and nonlinearity. Info. Manag. Business Rev. 7 (2), 113-130.

Kumar, J., Kumar, V., 2019. Drivers of brand community engagement. J. Retailing Consum. Serv. 54, 101949-101949.

Kumar, V., Ramachandran, D., Kumar, B., 2020. Influence of new-age technologies on marketing: a research agenda. J. Bus. Res. (in press).

Lee, S., 2018. Enhancing customers' continued mobile app use in the service industry. J. Serv. Market. 32 (6), 680-691.

Li, C.-Y., Fang, Y.-H., 2019. Predicting continuance intention toward mobile branded apps through satisfaction and attachment. Telematics Inf. 43, 101248.

Li, H., Gupta, A., Zhang, J., Flor, N., 2020. Who will use augmented reality? An integrated approach based on text analytics and field survey. Eur. J. Oper. Res. 281 (3), 502-516.

Li, T., Meshkova, Z., 2013. Examining the impact of rich media on consumer willingness to pay in online stores. Electron. Commer. Res. Appl. 12 (6), 449-461.

Liao, C., Palvia, P., Chen, J.-L., 2009. Information technology adoption behavior life cycle: toward a Technology Continuance Theory (TCT). Int. J. Inf. Manag. 29 (4), 309-320.

Loureiro, S.M.C., Guerreiro, J., Ali, F., 2020. 20 years of research on virtual reality and augmented reality in tourism context: a text-mining approach. Tourism Manag. 77, 104028.

Magrath, V., McCormick, H., 2013. Marketing design elements of mobile fashion retail apps. J. Fash. Mark. Manag. 17 (1), 115-134.

Martín-Consuegra, D., Díaz, E., Gómez, M., Molina, A., 2019. Examining consumer luxury brand-related behavior intentions in a social media context: the moderating role of hedonic and utilitarian motivations. Physiol. Behav. 200, 104-110.

McLean, G., 2018. Examining the determinants and outcomes of mobile app engagement a longitudinal perspective. Comput. Hum. Behav. 84, 392-403.

McLean, G., Wilson, A., 2019. Shopping in the digital world: examining customer engagement through augmented reality mobile applications. Comput. Hum. Behav. $101,210-224$.

Mehrabian, A., Russell, J.A., 1974. An Approach to Environmental Psychology. The MIT Press, Cambridge, MA, US.

Meola, A., 2019. Riseof M-commerce. In: Mobile Ecommerce Shopping Stats \& Trends in 2020. Business Insider. Retrieved from BusinessInsider.com website. https://www. businessinsider.com/mobile-commerce-shopping-trends-stats.

Mollen, A., Wilson, H., 2010. Engagement, telepresence and interactivity in online consumer experience. Reconciling Scholastic Manage. Perspect. 63 (9), 919-925.

Nikhashemi, Jebarajakirthy, Nusair, 2019. Uncovering the roles of retail brand experience and brand love in the apparel industry: non-linear structural equation modelling approach. J. Retailing Consum. Serv. 48, 122-135.

Pantano, E., Servidio, R., 2012. Modeling innovative points of sales through virtual and immersive technologies. J. Retailing Consum. Serv. 19 (3), 279-286.

Pantano, E., Timmermans, H., 2014. What is smart for retailing? Procedia Environ. Sci. 22, 101-107.

Park, M., Yoo, J., 2020. Effects of perceived interactivity of augmented reality on consumer responses: a mental imagery perspective. J. Retailing Consum. Serv. 52, 101912.

Picot-Coupey, K., Krey, N., Huré, E., Ackermann, C.-L., 2020. Still work and/or fun? Corroboration of the hedonic and utilitarian shopping value scale. J. Bus. Res. (in press).

Poushneh, A., 2018. Augmented reality in retail: a trade-off between user's control of access to personal information and augmentation quality. J. Retailing Consum. Serv. 41, 169-176.

Poushneh, A., Vasquez-Parraga, A.Z., 2017. Discernible impact of augmented reality on retail customer's experience, satisfaction and willingness to buy. J. Retailing Consum. Serv. 34, 229-234.

Rauschnabel, P.A., Felix, R., Hinsch, C., 2019. Augmented reality marketing: how mobile AR-apps can improve brands through inspiration. J. Retailing Consum. Serv. 49, 43-53.

Rese, A., Baier, D., Geyer-Schulz, A., Schreiber, S., 2017. How augmented reality apps are accepted by consumers: a comparative analysis using scales and opinions. Technol. Forecast. Soc. Change 124, 306-319 (d).

Scholz, J., Duffy, K., 2018. We ARe at home: how augmented reality reshapes mobile marketing and consumer-brand relationships. J. Retailing Consum. Serv. 44, 11-23. 
Schwarz, N., 2007. Attitude Construction: Evaluation in Context. Guilford Publications, pp. 638-656.

Sekaran, U., Bougie, R., 2016. Research Methods for Business: A Skill Building Approach. John Wiley \& Sons.

Smink, A.R., van Reijmersdal, E.A., van Noort, G., Neijens, P.C., 2020. Shopping in augmented reality: the effects of spatial presence, personalization and intrusiveness on app and brand responses. J. Bus. Res. 118, 474-485.

Steuer, J., 1992. Defining virtual reality: dimensions determining telepresence. J. Commun. 42 (4), 73-93.

Thrash, T., Moldovan, E., Oleynick, V., Maruskin, L., 2014. The psychology of inspiration. Social and Personality Psychol. Compass 8 (9), 495-510.

Trivedi, J.P., Trivedi, H., 2018. Investigating the factors that make a fashion app successful: the moderating role of personalization. J. Internet Commer. 17 (2), $170-187$ van Esch, P., Arli, D., Gheshlaghi, M.H., Andonopoulos, V., von der Heidt, T., Northey, G., 2019. Anthropomorphism and augmented reality in the retail environment. J. Retailing Consum. Serv. 49, 35-42.

Venkatesh, V., Thong, J., Xu, X., 2016. The unified theory of acceptance and use of technology (UTAUT). J. Assoc. Imformation Sys. 17 (5), 328-376.

Verhagen, T., Swen, E., Feldberg, F., Merikivi, J., 2015. Benefitting from virtual customer environments: an empirical study of customer engagement. Comput. Hum. Behav. 48, 340-357.

Wang, Rebecca Jen-Hui, 2020. Branded mobile application adoption and customer engagement behavior. Comput. Hum. Behav. 106, 106245.

Yim, M.Y.-C., Chu, S.-C., Sauer, P.L., 2017. Is augmented reality technology an effective tool for E-commerce? An interactivity and vividness perspective. J. Interact. Market. 39, 89-103. 